Article

\title{
Novel Magnetic Inorganic Composites: Synthesis and Characterization
}

\author{
Marco Natali ${ }^{1}\left(\right.$, Sergio Tamburini ${ }^{1}$, Roberta Bertani ${ }^{2}{ }^{\circledR}$, Daniele Desideri ${ }^{2}$, Mirto Mozzon ${ }^{2}$, Daniele Pavarin ${ }^{2}$,

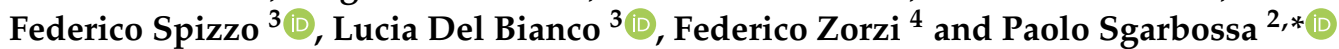

1 ICMATE, CNR, Corso Stati Uniti 4, 35127 Padova, Italy; marcostefano.natali@cnr.it (M.N.); sergio.tamburini@cnr.it (S.T.)

2 Department of Industrial Engineering, University of Padova, Via Marzolo 9 (P.S., R.B., M.M.), Via Gradenigo 6/a (D.D.) and Via Venezia 1 (D.P.), 35131 Padova, Italy; roberta.bertani@unipd.it (R.B.); daniele.desideri@unipd.it (D.D.); mirto.mozzon@unipd.it (M.M.); daniele.pavarin@unipd.it (D.P.)

3 Department of Physics and Earth Science, Polo Scientifico Tecnologico, University of Ferrara, Via G. Saragat 1 , 44122 Ferrara, Italy; federico.spizzo@unife.it (F.S.); lucia.delbianco@unife.it (L.D.B.)

4 CEASC, Via G. Jappelli 1/ A, 35121 Padova, Italy; federico.zorzi@unipd.it

* Correspondence: paolo.sgarbossa@unipd.it; Tel.: +39-049-827-5733

Citation: Natali, M.; Tamburini, S. Bertani, R.; Desideri, D.; Mozzon, M.; Pavarin, D.; Spizzo, F.; Del Bianco, L.; Zorzi, F.; Sgarbossa, P. Novel Magnetic Inorganic Composites: Synthesis and Characterization. Polymers 2021, 13, 1284. https:// doi.org/10.3390/polym13081284

Academic Editor: Ignazio Blanco

Received: 19 March 2021

Accepted: 13 April 2021

Published: 15 April 2021

Publisher's Note: MDPI stays neutral with regard to jurisdictional claims in published maps and institutional affiliations.

Copyright: (c) 2021 by the authors. Licensee MDPI, Basel, Switzerland. This article is an open access article distributed under the terms and conditions of the Creative Commons Attribution (CC BY) license (https:// creativecommons.org/licenses/by/ $4.0 /)$

\begin{abstract}
The addition of magnetic particles to inorganic matrices can produce new composites exhibiting intriguing properties for practical applications. It has been previously reported that the addition of magnetite to concrete improves its mechanical properties and durability in terms of water and chloride ions absorption. Here we describe the preparation of novel magnetic geopolymers based on two different matrices (G1 without inert aggregates and G2 with inert quartz aggregates) containing commercial $\mathrm{SrFe}_{12} \mathrm{O}_{19}$ particles with two weight concentrations, $6 \%$ and $11 \%$. The composites characterization, including chemical, structural, morphological, and mechanical determinations together with magnetic and electrical measurements, was carried out. The magnetic study revealed that, on average, the $\mathrm{SrFe}_{12} \mathrm{O}_{19}$ magnetic particles can be relatively well dispersed in the inorganic matrix. A substantial increase in the composite samples' remanent magnetization was obtained by embedding in the geopolymer $\mathrm{SrFe}_{12} \mathrm{O}_{19}$ anisotropic particles at a high concentration under the action of an external magnetic field during the solidification process. The new composites exhibit good mechanical properties (as compressive strength), higher than those reported for high weight concretes bearing a similar content of magnetite. The impedance measurements indicate that the electrical resistance is mainly controlled by the matrix's chemical composition and can be used to evaluate the geopolymerization degree.
\end{abstract}

Keywords: magnetic geopolymer composites; $\mathrm{SrFe}_{12} \mathrm{O}_{19}$ particles; morphological characterization; magnetic properties; impedance measurements

\section{Introduction}

The addition of magnetic particles to inorganic matrices has been explored to prepare new composites exhibiting intriguing properties for practical applications (see Magment ${ }^{\circledR}$ [1]). The addition of magnetite $\left(\mathrm{Fe}_{3} \mathrm{O}_{4}\right)$ to concrete has been proved to improve its mechanical properties (i.e., split tensile, flexural, and compressive strength [2]) and durability in terms of water and chloride ions absorption [2].

Concretes bearing different amounts of $\mathrm{Fe}_{3} \mathrm{O}_{4}$ or $\mathrm{Fe}_{3} \mathrm{O}_{4} @ \mathrm{SiO}_{2}$ nanoparticles also behave as electromagnetic wave absorbers (particularly of microwaves) and show $\gamma$-rays shielding properties, thus featuring a huge potential application in the construction of electromagnetic wave interference buildings [3-6]. The replacement of natural coarse aggregates with magnetite aggregates added in large amount to cement, fly ash, ground granulated blast furnace slag, and silica fume produce heavyweight self-compacting concretes and their addition under alkaline activation has been used to obtain heavyweight 
geopolymer concretes that provide proper protection from sources emitting harmful radiation in medical and nuclear industries [7-9]. An intriguing advantage derives from the synthetic versatility of concretes and geopolymers in terms of the possible introduction of a wide variety of additives able to absorb or dissipate electromagnetic waves [10-12].

Geopolymers [13] are inorganic binders different from regular concretes since they do not form calcium silicate hydrates for strength but are based on the polycondensation of silica and alumina with high alkali content. They have attracted the attention of researchers from different engineering fields owing to their modular environmentally friendly preparation procedure (low temperature, no harmful gas emission) [14], feasibility to incorporate high volumes of wastes or metal particles to produce value-added building materials with excellent physical and mechanical properties [15-17]. As an example, the incorporation of fly ash into geopolymers has been demonstrated to improve thermal stability and mechanical properties, thus providing an experimental basis for the utilization of solid waste soda residues and recycling of waste concrete $[18,19]$. As for the mechanical properties, it is known that they are improved by the incorporation and the homogeneous distribution of nanomaterials due to the formation of a denser microstructure, but the identification of the optimum content of nanomaterials is very important to achieve the respective high performance in strength as well as workability [20]. In the case of the addition of nanosized $\mathrm{Fe}_{2} \mathrm{O}_{3}$, it was reported that in Portland cement composites, a homogeneous microstructure was obtained with magnetite loading lower than $10 \% w / w$ with an improvement of the compressive strength by $60 \%$. Higher added amounts produced aggregation of the nanoparticles with a detrimental effect on the mechanical performance of the material [9].

Recently, geopolymers containing magnetite or maghemite nanoparticles have been prepared and applied in environmental remediation processes, such as water decolorization [21,22], arsenic [23] or heavy metals [24] removal from aqueous solutions.

Geopolymers and magnetic geopolymers have also been proposed as low-cost, effective catalysts for environment governance by "end-of-pipe" treatments, such as photocatalytic degradation of dye wastewater or gas purification and have been employed for hydrogen and biodiesel production as well as in green heterogeneous catalytic processes [25,26].

The preparation of magnetic inorganic composites has also attracted considerable interest as candidate materials for high-frequency electronic components, such as miniaturized antennas and inductors $[27,28]$.

It is to note that recently a concrete based on $\mathrm{SrFe}_{12} \mathrm{O}_{19}$ particles dispersed in alumina cement has been investigated as a sacrificial material for ex-vessel core catcher in nuclear power plants [29,30], and $\mathrm{SrFe}_{12} \mathrm{O}_{19} / \mathrm{MFe}_{2} \mathrm{O}_{4}(\mathrm{M}=\mathrm{Zn}, \mathrm{Ni})$ composites have been shown to exhibit microwave absorption properties $[4,31]$.

In the present work, the preparation of novel magnetic geopolymers, based on two different matrices containing commercial $\mathrm{SrFe}_{12} \mathrm{O}_{19}$ particles, with two different concentrations, is described. The objective was to investigate the influence of composition and experimental conditions for preparation on the morphology, dispersion of $\mathrm{SrFe}_{12} \mathrm{O}_{19}$ particles, electrical and mechanical properties. Particularly attractive is the study of the magnetic properties of the composites and of their modification when solidification of the geopolymers is performed in the presence of an external magnetic field. The research project's target is to design magnetic inorganic composites to apply for pollutant removal [32-34] and heterogeneous catalytic processes [35] on a large scale.

\section{Materials and Methods}

\subsection{Materials}

Reagents used for geopolymer preparation were: (a) metakaolin (MK) (medium particle size $1.2 \mu \mathrm{m}$, BET $6.031 \mathrm{~m}^{2} / \mathrm{g}$ ) produced in-house by calcining in an oven for $5 \mathrm{~h}$ commercial kaolinite powder (MiMac Srl, CE, Italy) at $750^{\circ} \mathrm{C}$; (b) granulated blast furnace slag (GBFS) from the ILVA Metallurgical Plant (Taranto, Italy) reduced to a grain size of 60-400 $\mu \mathrm{m}$ before use; (c) potassium silicate activator (Ksil) with a molar modulus (MM) $\mathrm{SiO}_{2} / \mathrm{K}_{2} \mathrm{O}$ of $1 / 1.3$ and dry matter concentration of $45 \%$, prepared in-house by mixing 
a $50 \% \mathrm{w}$ colloidal silica dispersion and $\mathrm{KOH}$ pellets with distilled water at least $24 \mathrm{~h}$ before use.

The commercial magnetic particles of $\mathrm{SrFe}_{12} \mathrm{O}_{19}$ ferrite (Industrie ILPEA s.p.a.) were micrometric in size and polycrystalline. Two different types of $\mathrm{Sr}$ ferrite particles were used, namely isotropic particles (product code: $\mathrm{P} 02-\mathrm{Sr}-\mathrm{D}$ ), is- $\mathrm{SrFe}_{12} \mathrm{O}_{19}$, and anisotropic particles (product code: $\mathrm{P} 11$ ), anis- $\mathrm{SrFe}_{12} \mathrm{O}_{19}$.

The $\mathrm{SrFe}_{12} \mathrm{O}_{19}$ ferrite has a hexagonal crystalline structure and is a hard ferrimagnetic phase with magnetocrystalline anisotropy coefficient $\mathrm{K}=3.6 \cdot 10^{6} \mathrm{erg} / \mathrm{cm}^{3}$ [36], and an easy axis parallels to the c crystallographic axis [37]. In each of the isotropic particles, the crystallite orientation is random, and therefore, no preferential magnetocrystalline anisotropy direction exists. This implies the existence of a magnetic configuration characterized by magnetic domains with different orientations (for simplicity of description, it can be assumed that the magnetic domains coincide with the crystallites). On the contrary, each anisotropic particle is textured; namely, the crystallites have a preferred orientation resulting in the appearance of a preferential anisotropy direction, i.e., of a magnetization easy axis. In this case, a magnetic configuration with parallel domains is predictable.

\subsection{Preparation of the Samples}

New inorganic magnetic composites were prepared by using an alkaline activation process carried out in the presence of commercial magnetic particles. Details of sample preparation are as follows: $\mathrm{MK}$, slag, $\mathrm{k}$-silicate $\left(\mathrm{SiO}_{2} / \mathrm{K}_{2} \mathrm{O}=1.3\right.$, dry matter $\left.=45 \%\right)$ and $\mathrm{H}_{2} \mathrm{O}$ were mixed by hand in a beaker, using the proportions indicated in Table 1 , using a spatula; this process was assisted by pneumatic vibration for $3 \mathrm{~min}$ to start the reaction of MK and slag reagents with the activator solution.

Table 1. Labeling and composition of the G1 and G2 matrices.

\begin{tabular}{crrrcc}
\hline Sample & MK & \multicolumn{1}{c}{ Slag } & Activator & Quartz Aggregates & Water \% w/w on Total Wet Amount \\
\hline G1 & 1 & 1 & K $1.3,45 \%$ & none & ca. 10 \\
G2 & 1 & 1 & K $1.3,45 \%$ & $\mathrm{I} 84^{1} ; 3.2$ & 7.2 \\
\hline
\end{tabular}

${ }^{1}$ I84 = ventilated quartz, particle size $<160 \mu \mathrm{m}$.

At this point, inert aggregates and magnetic particles could be added; then, the mixture was further mixed under vibration for about $10 \mathrm{~min}$, and a dense, uniform and highly thixotropic paste was formed. The paste was dispensed with a spatula into the appropriate sample molds for each sample type and further vibrated briefly to homogenize the paste inside the mold. Samples were hardened by curing at $60{ }^{\circ} \mathrm{C}$ in an oven for $24 \mathrm{~h}$ keeping the molds inside a sealed plastic bag at saturated humidity provided by a wet cloth inside the bag. After curing and demolding, samples were further stored for 7 days in a sealed plastic bag.

Two different matrices were prepared: a matrix labeled G1, where no inert aggregates were added, and a matrix labeled G2, including inert quartz aggregates in an amount of $53 \%$ of the total dry weight of the blend. Quartz aggregates were added to the matrix to try to reduce the risk of aggregation of magnetic particles. Reagents and mix ratios of the two matrices are reported in Table 1. Magnetic particles were added with a mass concentration of about $6 \%$ and about $11 \%$ to both G1 and G2 matrices by keeping approximately constant the amount of extra water at about $10 \%$ in mass for G1 and at about $6-7 \%$ for G2. For matrix G1, the $6 \%$ composition yielded a very fluid mixture as the amounts of aggregates were very low. Therefore, in this case, additional samples labeled as DENSE were prepared by reducing the amount of added water to $2-3 \%$ in mass, thus keeping a workability (thixotropy) mixture comparable to that of the $11 \%$ composition.

The labeling of the geopolymer samples containing isotropic and anisotropic $\mathrm{SrFe}_{12} \mathrm{O}_{19}$ ferrite magnetic particles includes "is" and "anis", respectively (Scheme 1). 


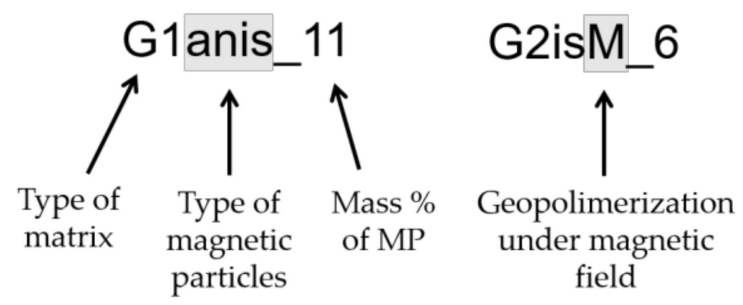

Scheme 1. Labeling scheme for the magnetic geopolymer composite samples (MP $=\mathrm{SrFe}_{12} \mathrm{O}_{19}$ magnetic particles).

As described in more detail in Section 2.3.2, some of the magnetic geopolymer samples were prepared by applying an external magnetic field during the curing process to study whether and to what extent this affected the spatial and magnetic configuration of the embedded particles. Hence, the name of magnetized samples included the " $\mathrm{M}$ " suffix (Scheme 1). The list and labeling of the samples are reported in Table 2.

Table 2. Samples' composition and density values.

\begin{tabular}{|c|c|c|c|}
\hline Sample & $\begin{array}{l}\text { Magnetic Particles } \\
\text { (\% Dry Weight) }\end{array}$ & $\begin{array}{l}\text { Extra Water } \\
\text { (\% Wet Weight) }\end{array}$ & Density $\left(\mathrm{g} / \mathrm{cm}^{3}\right)^{1}$ \\
\hline $\begin{array}{l}\text { anis- } \\
\mathrm{SrFe}_{12} \mathrm{O}_{19}\end{array}$ & 100 & - & - \\
\hline is- $\mathrm{SrFe}_{12} \mathrm{O}_{19}$ & 100 & - & - \\
\hline G1 & 0 & 10 & 2.02 \\
\hline G2 & 0 & 7.2 & 2.19 \\
\hline G1anis_6 & 6 & 10.2 & 2.19 \\
\hline G1is_6 & 6 & 10.2 & 2.21 \\
\hline G1anis_6DENSE & 6 & 3.3 & 2.22 \\
\hline G1is_6DENSE & 6 & 2.3 & 2.24 \\
\hline G1anis_11 & 11.2 & 9.8 & 2.19 \\
\hline G1anisM_11 & 11.2 & 9.8 & 2.18 \\
\hline G1is_11 & 10.2 & 9.8 & 2.21 \\
\hline G1isM_11 & 10.2 & 9.9 & 2.30 \\
\hline G2anis_6 & 6 & 6.4 & 2.29 \\
\hline G2anisM_6 & 5.9 & 6.4 & 2.32 \\
\hline G2is_6 & 6 & 5.9 & 2.25 \\
\hline G2isM_6 & 5.9 & 5.9 & 2.40 \\
\hline G2anis_11 & 11.2 & 8.3 & 2.34 \\
\hline G2is_11 & 11.2 & 8.3 & 2.36 \\
\hline
\end{tabular}

${ }^{1}$ data are the average of five independent measurements.

\subsection{Characterization Techniques}

\subsubsection{Chemical, Structural, and Morphological Characterization}

The microanalysis and the samples' morphology were studied by environmental scanning electron microscopy (ESEM) with an embedded Quanta 200 FEI-EDX embedded.

The density of samples was measured according to UNI EN 206-2016 [38].

Fourier-transform infrared spectroscopy (FTIR) spectra of powders were obtained on a Nicolet spectrophotometer Avatar 320 as KBr pellets. For each sample, 32 scans were recorded in the range $4000-400 \mathrm{~cm}^{-1}$ in the transmittance mode with a resolution of $4 \mathrm{~cm}^{-1}$.

Raman spectroscopic determinations were carried out using a continuous wave linearly polarized ( $514.5 \mathrm{~nm}$ ) wavelength, $2.41 \mathrm{eV}, 16 \mathrm{~mW}$ power, instrument. The laser beam was focused by a $100 \times$ objective lens, resulting in a spot of about $1 \mu \mathrm{m}$ in diameter.

Solid-state NMR experiments, carried out on the non-magnetic materials, were performed on a Bruker AVANCE III spectrometer 300 (magnetic field of 7.0 T corresponding to ${ }^{27} \mathrm{Al}$ and ${ }^{29} \mathrm{Si}$ Larmor frequencies of 78.066 and $59.623 \mathrm{MHz}$, respectively) equipped for solid-state analysis in $4 \mathrm{~mm}$ diameter zirconia rotors with Kel-F caps. The magic angle was accurately adjusted before data acquisition using $\mathrm{KBr} .{ }^{29} \mathrm{Si}$ chemical shifts were externally 
referenced to solid tetrakis(trimethylsilyl)silane at $-9.8 \mathrm{ppm}$ (in relation to TMS), and ${ }^{27} \mathrm{Al}$ chemical shifts are externally referenced to $\mathrm{AlCl}_{3} \cdot 6 \mathrm{H}_{2} \mathrm{O}(0 \mathrm{ppm})$. The semiquantitative 29Si single-pulse experiments were collected at a spinning frequency of $6 \mathrm{kHz}$, a recycling delay of $60 \mathrm{~s}$ and 2000 transients. ${ }^{27} \mathrm{Al}$ experiments were collected at a spinning frequency of $13 \mathrm{kHz}$ with a pulse of $1.0 \mu \mathrm{s}$ and a recycle time of $2 \mathrm{~s}$. About 2000 scans were needed using a single pulse experiment. The signal patterns of the spectra were deconvoluted with the DMFT program using the Gaussian/Lorentz curve, which leads to the best result [39].

X-ray diffraction (XRD) measurements were carried out using a PANalytical X'Pert Pro diffractometer equipped with a Co X-ray tube and a real-time multiple strip (RTMS) detector (X'Celerator). Panalytical High Score Plus software and Panalytical ICSD database were used for phase identification. Full-scale XRD patterns are given in Supplementary Materials (Figures S1-S8). Meanwhile, in the paper are reported XRD patterns with reduced angular ranges containing only the main peaks of the phases of interest.

Thermogravimetric measurements with a differential thermal analyzer (TG-DTA) were carried out on a Netzsch STA 449 thermoanalytical equipment in the $30-1200{ }^{\circ} \mathrm{C}$ range in alumina crucibles in air and with a heating rate of $10 \mathrm{~K} / \mathrm{min}$, using neutral alumina as reference material.

\subsubsection{Magnetic Characterization}

For the magnetic study, for each type of sample, two cylindrical specimens were prepared with dimensions of $5 \mathrm{~mm}$ (diameter) $\times 30 \mathrm{~mm}$ (length) inside small polyethylene sealed tubular containers. One of the cylinders, for some selected samples, was solidified under magnetic field by placing it, while in the fluid state, between two cubic $\left(2 \times 2 \times 2 \mathrm{~cm}^{3}\right)$ $\mathrm{SmCo}_{5}$ block magnets kept apart at $3.5 \mathrm{~cm}$ of distance and keeping the cylinder between the magnets during the subsequent curing stage at $60^{\circ} \mathrm{C}$ for about $12 \mathrm{~h}$. The magnetic field $\mathrm{H}_{\mathrm{APP}}$ experienced by the sample was $\sim 3.5 \mathrm{kOe}$. Magnetic hysteresis measurements were performed using a Quantum Design superconducting quantum interference device (SQUID) magnetometer at temperatures $\mathrm{T}=20 \mathrm{~K}$ and $300 \mathrm{~K}$, with a maximum applied field of $50 \mathrm{kOe}$. Both the isotropic and anisotropic commercial $\mathrm{SrFe}_{12} \mathrm{O}_{19}$ magnetic particles were investigated in the form of powder. As for the magnetic geopolymers, a piece of $5 \mathrm{~mm}$ in length, suitable for SQUID analysis, was cut at the center of each of the prepared cylinders.

\subsubsection{Electrical Characterization}

The geopolymer electrical characterization was performed by doing measurements of impedance on samples prepared in the following way. Disk samples of diameter $5 \mathrm{~cm}$ and thickness around $1 \mathrm{~cm}$ were prepared with formulations: G1_matrix, G1is_6_norm, and G1is_6_highW, as well as a sample G1is_6_highK using a higher amount of k-silicate, Ksil (weight rations MK:slag: Ksil = 1:1:2 instead of 1:1:1.33) (Table 3).

Table 3. Composition of the samples used for electrical characterization.

\begin{tabular}{ll}
\hline Sample & Formulation \\
\hline G1_matrix & MK:slag:Ksil $=1: 1: 1.33$, extra water $=0$ \\
G1is_6_norm & MK:slag:Ksil $=1: 1: 1.30$, is- $-\mathrm{SrFe}_{12} \mathrm{O}_{19}=5.99 \%$, extra water $=0$ \\
G1is_6_highW & MK:slag:Ksil $=1: 1: 1.30$, is-SrFe ${ }_{12} \mathrm{O}_{19}=6.11 \%$, extra water $=4.36 \%$ \\
G1is_6_highK & MK:slag:Ksil $=1: 1: 2$, is- $_{-} \mathrm{SrFe}_{12} \mathrm{O}_{19}=5.37 \%$, extra water $=0$ \\
\hline
\end{tabular}

The configuration of a parallel plate capacitor with a dielectric between its plates was realized. Starting from the geopolymer disk samples, the two opposite circular surfaces of each disk were painted with silver conductive paint and then a rectangular piece of copper tape, with conductive glue and a wire welded on it, was put on each one of the two opposite painted surfaces. The equivalent electrical model of this configuration was a resistor and a capacitor in parallel (R-C parallel), plus an inductor, connected in series with the R-C parallel, for the electrical model of the two wires. Measurements were performed by using two LCR meters, a GW Instek LCR-6300 (frequency range $10 \mathrm{~Hz}-300 \mathrm{kHz}$ ) and an 
Agilent 4285A (frequency range $75 \mathrm{kHz}-30 \mathrm{MHz}$ ). The two instruments have shown a very good agreement in the frequency range $75 \mathrm{kHz}-300 \mathrm{kHz}$, where both instruments could be used. The inductor that modeled the electrical behavior of the two connection wires (each one about $8 \mathrm{~cm}$ long) was roughly estimated as the inductance of $100 \mathrm{nH}$, value based on the assumption of an inductance per-unit-length of $1 \mu \mathrm{H} / \mathrm{m}$. Impedance experimental data, in the frequency range $10 \mathrm{~Hz}-30 \mathrm{MHz}$, have shown that the inductive contribution above indicated could be neglected and therefore, the final model was given by only the $\mathrm{R}-\mathrm{C}$ parallel. The measured resistance and capacitance were used for the estimation of the conductivity and relative permittivity of each sample. With the geometry and by using the relation of the resistance of a cylindrically shaped uniform material, the estimation of the conductivity was obtained. With the geometry and the relation of the capacitance of a parallel plate capacitor, the estimation of the relative permittivity was calculated. The electrical conductivity of the ferrite magnetic powders in the explored frequency range $(10 \mathrm{~Hz}-30 \mathrm{MHz})$ was not expected to significantly contribute to conductivity because of its very low conductivity [40], several orders of magnitude lower than our geopolymer matrix, and the small percentage of added powder.

\subsubsection{Mechanical Characterization}

For mechanical measurements, a series of rectangular prism samples of dimensions $22 \times 22 \times 44 \mathrm{~mm}^{3}$ were prepared to determine their compressive strength. Mechanical measurements of compressive strength were performed in triplicate on samples aged for 7 days after curing; in this case, the samples were not magnetized during the molding process. Compressive strength was measured using an Unitronic S205 test machine (Matest, BG, Italy) equipped with a $50 \mathrm{kN}$ load cell.

\section{Results and Discussion}

\subsection{Characterization of the $\mathrm{SrFe}_{12} \mathrm{O}_{19}$ Particles}

It is known that the structural and magnetic properties of $\mathrm{SrFe}_{12} \mathrm{O}_{19}$ particles may change depending on the specific synthesis route [41-43]. Therefore, we have carried out a characterization of the commercial Sr hexaferrite particles used to prepare the composite geopolymer samples.

The morphology of the Sr ferrite particles was investigated by ESEM. The results are shown in Figure 1.

The anisotropic particles are in the form of platelets that are often stacked (Figure 1a,b), with a thickness of some tenths of micron along the c crystallographic axis, as indicated by the producer, and a lateral size of some microns. The isotropic particles are in the form of platelets too (Figure 1c,d), but, compared to the anisotropic ones, they appear slightly smaller on the average and show a somewhat more rounded shape, possibly due to a lower crystallinity degree, i.e., a smaller size of the crystalline grains. The Energy Dispersive X-ray analyses (EDX) showed that isotropic and anisotropic $\mathrm{SrFe}_{12} \mathrm{O}_{19}$ powders had a different average composition, as reported in Table 4, with a higher Ba content in the anisotropic powder. A detailed analysis of single particles of the anisotropic powder showed that they contain variable amounts of Ba. The ESEM images showed that, in the case of the isotropic powder, some groups of larger particles are present where the $\mathrm{Ba}$ content is lower than the detection threshold.

Table 4. Composition of the is- $\mathrm{SrFe}_{12} \mathrm{O}_{19}$ and anis-SrFe ${ }_{12} \mathrm{O}_{19}$ powders. The data were obtained by EDX determinations and represent the average of five measurements on different samples.

\begin{tabular}{|c|c|c|c|c|}
\hline \multirow{2}{*}{ Element } & \multirow{2}{*}{$\begin{array}{r}\text { is-SrFe }{ }_{12} \mathrm{O}_{19} \\
w / w \%\end{array}$} & \multicolumn{3}{|c|}{ anis- $\mathrm{SrFe}_{12} \mathrm{O}_{19}$} \\
\hline & & Atomic \% & $w / w \%$ & Atomic \% \\
\hline $\mathrm{O}$ & 18.4 & 44.2 & 22.2 & 51.3 \\
\hline $\mathrm{Sr}$ & 5.7 & 4.4 & 4.5 & 1.9 \\
\hline $\mathrm{Ba}$ & 1.9 & 0.6 & 4.8 & 1.3 \\
\hline $\mathrm{Fe}$ & 74.0 & 50.8 & 68.5 & 45.5 \\
\hline
\end{tabular}


(a)

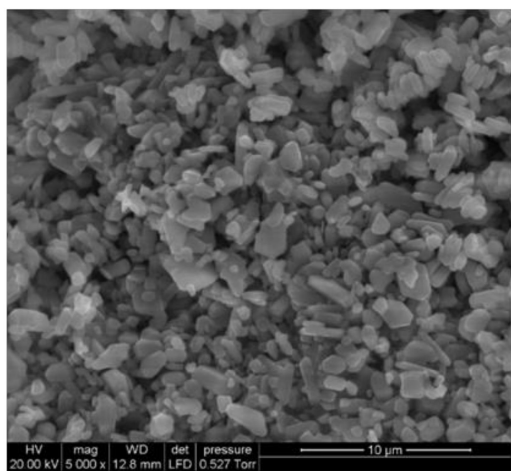

(c)

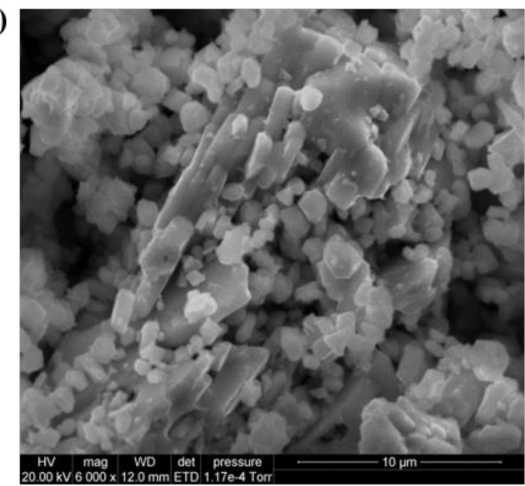

(b)

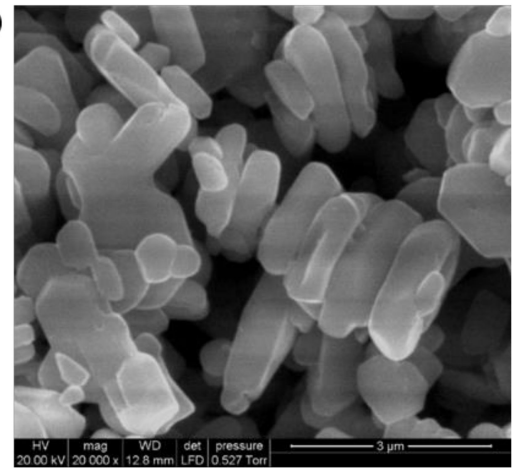

(d)

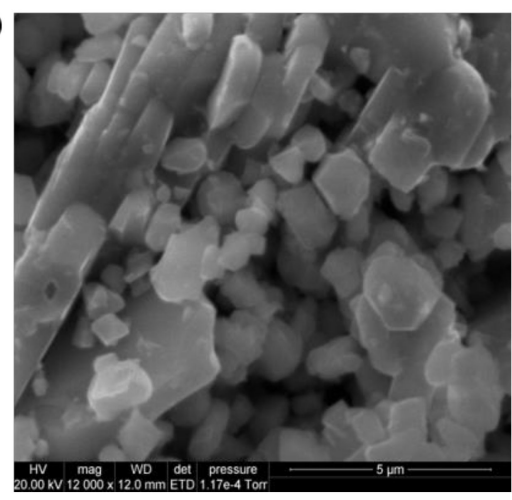

Figure 1. Environmental scanning electron microscopy (ESEM) pictures were collected on the anisotropic $\mathrm{SrFe}_{12} \mathrm{O}_{19}$ ferrite samples $(\mathbf{a}, \mathbf{b})$ and on the isotropic ferrite ones $(\mathbf{c}, \mathbf{d})$ at different magnifications.

In both the FTIR spectra of is- $\mathrm{SrFe}_{12} \mathrm{O}_{19}$ and anis- $\mathrm{SrFe}_{12} \mathrm{O}_{19}$ (Figure 2), the characteristic peaks at around 620 and $540 \mathrm{~cm}^{-1}$ (the asterisks in Figure 2) together with those at around 600 and $440 \mathrm{~cm}^{-1}$ (the circles in Figure 2, assigned to the $\mathrm{Fe}-\mathrm{O}$ bending of $\mathrm{Fe}-\mathrm{O}_{4}$, tetrahedral, and Fe-O stretching of $\mathrm{Fe}^{-} \mathrm{O}_{6}$, octahedral, respectively) are present. The slight difference in the relative intensities of the peaks can be related to the different shapes and compositions [44]. There is no evidence of adsorbed water in both cases.

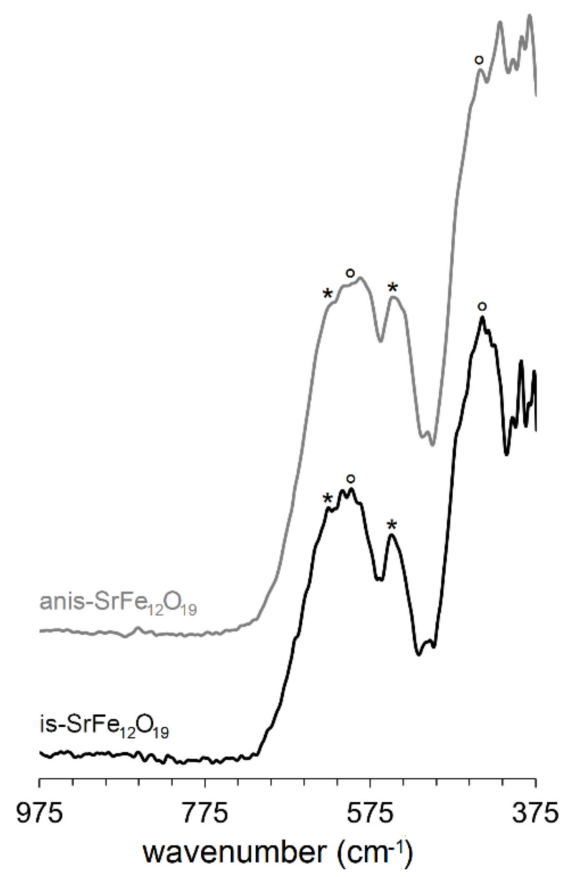

Figure 2. FTIR spectra of is- $\mathrm{SrFe}_{12} \mathrm{O}_{19}$ and anis- $\mathrm{SrFe}_{12} \mathrm{O}_{19}$ in the range $975-375 \mathrm{~cm}^{-1}$. 
In Figure 3, the XRD patterns of is- $\mathrm{SrFe}_{12} \mathrm{O}_{19}$ and anis- $\mathrm{SrFe}_{12} \mathrm{O}_{19}$ are reported. Both profiles show typical peaks of hexagonal $\mathrm{SrFe}_{12} \mathrm{O}_{19}$ [45], which match with the reference pattern 98-018 4961 (Panalytical ICSD database) in the case of isotropic powder and are also accompanied by the peaks of the $\mathrm{Ba}_{0.98} \mathrm{Fe}_{11.93} \mathrm{O}_{18.84}$ (reference pattern 98-008-7406) in the case of the anisotropic ones. The presence of $\mathrm{Ba}$ ferrite in anis- $\mathrm{SrFe}_{12} \mathrm{O}_{19}$ is in agreement with the results of the EDX analysis (Table 4). The common impurities of unreacted $\mathrm{Fe}_{2} \mathrm{O}_{3}$ and $\mathrm{SrCO}_{3}$ precursors are present in very low amounts.
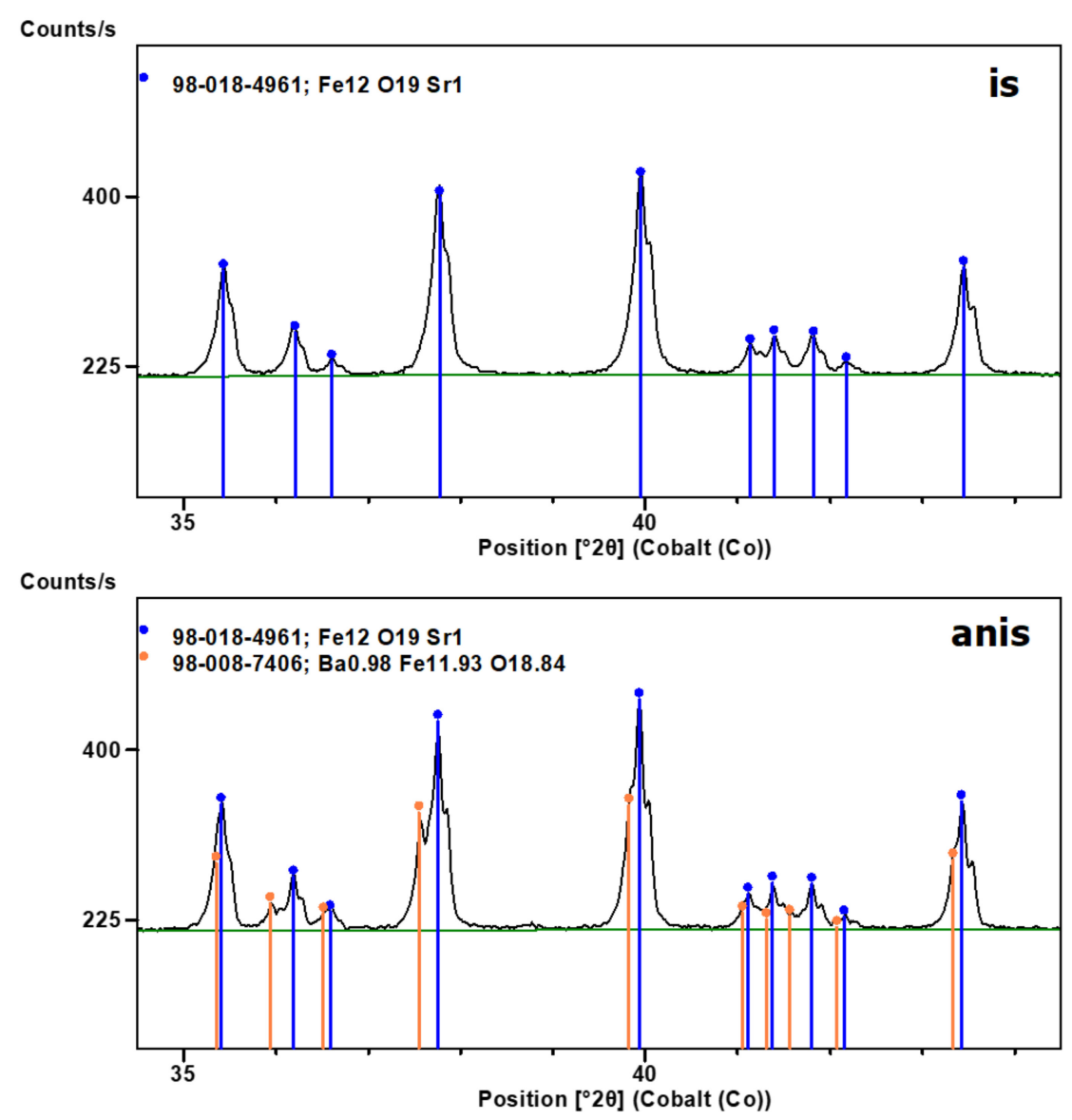

Figure 3. $\mathrm{XRD}$ patterns of is- $\mathrm{SrFe}_{12} \mathrm{O}_{19}$ and anis- $\mathrm{SrFe}_{12} \mathrm{O}_{19}$.

The magnetic hysteresis loops of both the is- $\mathrm{SrFe}_{12} \mathrm{O}_{19}$ and the anis- $\mathrm{SrFe}_{12} \mathrm{O}_{19}$ particles are shown in Figure 4. Nominal values of the saturation magnetization for the $\mathrm{SrFe}_{12} \mathrm{O}_{19}$ phase are $\mathrm{M}_{\mathrm{S}} \sim 74 \mathrm{emu} / \mathrm{g}$ at room temperature and $\mathrm{M}_{\mathrm{S}} \sim 104 \mathrm{emu} / \mathrm{g}$ at $0 \mathrm{~K}$ [37].
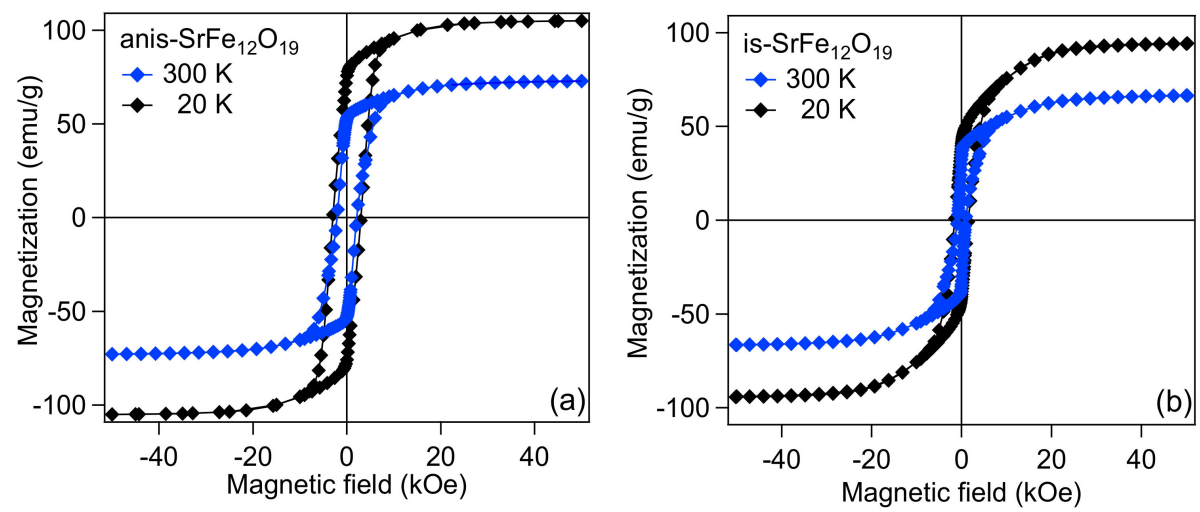

Figure 4. Magnetic hysteresis loops collected on the anis- $\mathrm{SrFe}_{12} \mathrm{O}_{19}(\mathbf{a})$ and the is- $\mathrm{SrFe}_{12} \mathrm{O}_{19}(\mathbf{b})$ ferrite particles at $\mathrm{T}=20 \mathrm{~K}$ (black markers) and $\mathrm{T}=300 \mathrm{~K}$ (blue markers). 
As reported in Table 5, in the anisotropic particles, we have measured $\mathrm{M}_{\mathrm{S}} \sim 75 \mathrm{emu} / \mathrm{g}$ and $\mathrm{M}_{\mathrm{S}} \sim 107 \mathrm{emu} / \mathrm{g}$ at $\mathrm{T}=300 \mathrm{~K}$ and $\mathrm{T}=20 \mathrm{~K}$, respectively, in agreement with the expected values. In fact, the presence of traces of Ba ferrite, revealed by XRD (Figure 3), does not affect the magnetization since $\mathrm{Sr}$ and Ba ferrites have similar magnetic properties [46]. The values of $\mathrm{M}_{\mathrm{S}}$ for the isotropic particles are slightly smaller, namely $69 \mathrm{emu} / \mathrm{g}$ at $300 \mathrm{~K}$ and $\sim 97 \mathrm{emu} / \mathrm{g}$ at $20 \mathrm{~K}$.

Table 5. Saturation magnetization $M_{S}$, coercivity $H_{C}$ and squareness parameter $M_{R}$, at $T=300 \mathrm{~K}$ and $20 \mathrm{~K}$, for the samples labeled as indicated in column 1.

\begin{tabular}{|c|c|c|c|c|c|c|}
\hline \multirow{2}{*}{ Sample } & \multicolumn{3}{|l|}{$300 \mathrm{~K}$} & \multicolumn{3}{|l|}{$20 \mathrm{~K}$} \\
\hline & $M_{S}(e m u / g) \pm 2 \%$ & $\mathrm{H}_{\mathrm{C}}(\mathrm{kOe}) \pm \mathbf{1} \%$ & $M_{R} \pm 2 \%$ & $M_{S}(e m u / g) \pm 2 \%$ & $\mathrm{H}_{\mathrm{C}}(\mathrm{kOe}) \pm \mathbf{1 \%}$ & $M_{R} \pm 2 \%$ \\
\hline is- $\mathrm{SrFe}_{12} \mathrm{O}_{19}$ & 69 & 0.95 & 0.48 & 97 & 1.51 & 0.44 \\
\hline anis- $\mathrm{SrFe}_{12} \mathrm{O}_{19}$ & 75 & 2.11 & 0.70 & 107 & 2.97 & 0.71 \\
\hline
\end{tabular}

The loops exhibit a wasp-waist-like shape, i.e., they narrow at the center, the effect being particularly evident in the isotropic particles. This is often observed in samples made of hard and soft magnetic elements mixed together [47,48]. In our case, this feature may indicate that the Sr ferrite powders are magnetically not homogeneous and consist of particles with different anisotropy, possibly due to some stoichiometric and structural disorder, as revealed by EDX analysis (Table 4). This would also account for the reduced $\mathrm{M}_{\mathrm{S}}$ value measured in is- $\mathrm{SrFe}_{12} \mathrm{O}_{19}[49,50]$. However, the wasp-waist-like shape may appear more or less pronounced depending not just on the relative fractions of different magnetic particles but also depending on their respective magnetization and coercivity and on how they are mixed and possibly interact through both exchanges and dipolar interactions. It is quite well demonstrated that the magnetic moments of fully exchange-coupled soft and hard nanocrystallites reverse coherently under an applied magnetic field, giving rise to a loop typical of a single magnetic phase, whereas a constricted loop can be observed in the case of incomplete coupling [51-53].

It has recently been shown that colloids of mixed iron oxide nanoparticles with different coercivity values, although of the same order of magnitude (ratio 1:3), exhibited magnetic loops that did not reveal the presence of two distinct populations, actually [54]. Wasp-waist-like loops were measured in assemblies of nanoparticles, consisting of the same magnetic phase, due to the action of dipolar interactions only [55,56]. Hence, the casuistry is very wide and articulated. In the perspective of comparing the loops in Figure 4 for the starting is- $\mathrm{SrFe}_{12} \mathrm{O}_{19}$ and anis- $\mathrm{SrFe}_{12} \mathrm{O}_{19}$ particles and those measured in the geopolymer samples shown below (Section 3.3.3), we can generally say that the observation of a waspwaist-like hysteresis loop in a certain assembly of magnetic particles is a sort of fingerprint of a specific arrangement and/or magnetic interacting state of the particles themselves.

From the loops, we have derived the squareness parameter, indicated with $\mathrm{M}_{R}$, corresponding to the ratio between the remanent and the saturation magnetization values. $M_{R}$ is higher in the anisotropic particles, both at $300 \mathrm{~K}$ and $20 \mathrm{~K}$ (Table 5).

According to the Stoner and Wohlfarth model for a ferromagnetic element with uniaxial anisotropy, a perfectly squared hysteresis loop (i.e., $M_{R}=1$ ) is measured by applying the magnetic field parallel to the anisotropy axis [57]. The same occurs for an assembly of these magnetic elements, provided that they are not interacting and that their anisotropy axes are all parallel to the applied magnetic field. However, in the case of an assembly of magnetic elements noninteracting and with random spatial orientation of the anisotropy axes, $\mathrm{M}_{\mathrm{R}}=0.5$.

The high values of $\mathrm{M}_{\mathrm{R}}$ found in the anisotropic Sr-ferrite particles indicate that their preferential anisotropy axes, i.e., the c crystallographic axes, were quite well aligned with the external field during the loop measurement. Indeed, this is quite unexpected since we did nothing to obtain this degree of spatial order of the particles. It should be considered that to be analyzed by SQUID, a small number of $\mathrm{SrFe}_{12} \mathrm{O}_{19}$ was put at the bottom of a 
polymer capsule and slightly pressed to avoid that they moved during the measurement. The capsule had an elongated shape, and during the measurement, the field was applied parallel to its major axis. Hence, a likely explanation is that, due to their flattened shape, the particles, forming stacks as observed by ESEM, lie on the bottom of the capsule. The isotropic platelets are expected to show the same tendency. However, a lower $\mathrm{M}_{\mathrm{R}}$ was measured in this case because the isotropic particles do not possess a preferential anisotropy axis. $M_{R}$ is slightly smaller than 0.5 , in line with the Stoner and Wohlfarth model, since the whole set of crystallites, of which the particles consist, represents an assembly of magnetic elements with randomly oriented anisotropy axes.

This description may also account for the lower $\mathrm{H}_{\mathrm{C}}$ measured in is- $\mathrm{SrFe}_{12} \mathrm{O}_{19}$ compared to that of anis- $\mathrm{SrFe}_{12} \mathrm{O}_{19}$ (Table 5) since the Stoner Wohlfarth model predicts that the coercivity of the random assembly is about half of that measured in the ordered one. In particular, at $\mathrm{T}=300 \mathrm{~K}$, we measured $\mathrm{H}_{\mathrm{C}} \sim 0.95 \mathrm{kOe}$ in is- $\mathrm{SrFe}_{12} \mathrm{O}_{19}$ and $\mathrm{H}_{\mathrm{C}} \sim 2.11 \mathrm{kOe}$ in anis-SrFe ${ }_{12} \mathrm{O}_{19}$. However, in the case of our samples, the situation is more complex because the particles are very close to each other and so certainly subjected to magnetic interactions, which are known to alter the coercivity compared to that of an assembly of isolated particles. In particular, dipolar interactions tend to decrease $\mathrm{H}_{\mathrm{C}}[55,56,58]$, and the same can be observed in exchange-coupled particles [59,60]. Moreover, the is- $\mathrm{SrFe}_{12} \mathrm{O}_{19}$ and anis-SrFe ${ }_{12} \mathrm{O}_{19}$ particles exhibit constricted hysteresis loops (Figure 4). Therefore, the $\mathrm{H}_{\mathrm{C}}$ values of the isotropic and anisotropic particles should not be compared in the framework of the Stoner and Wohlfarth description.

\subsection{Characterization of the G1 and G2 Matrices}

In Figure 5, the ESEM images of the G1 and G2 matrices are shown. The composition reported in Table 6, as an average of at least five measurements, agrees with the presence in matrix G2 of added quartz; in both cases, the morphology appears highly porous, with G1 less compact than G2.

(a)

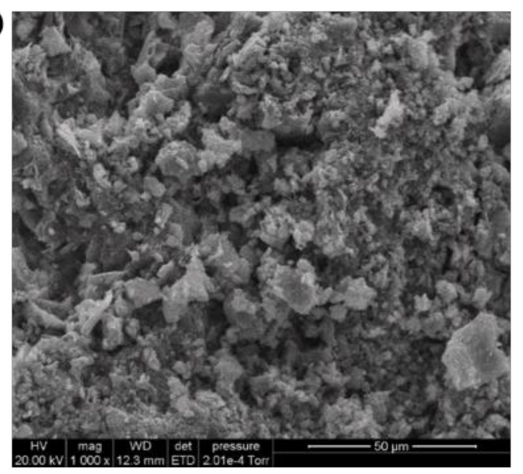

(b)

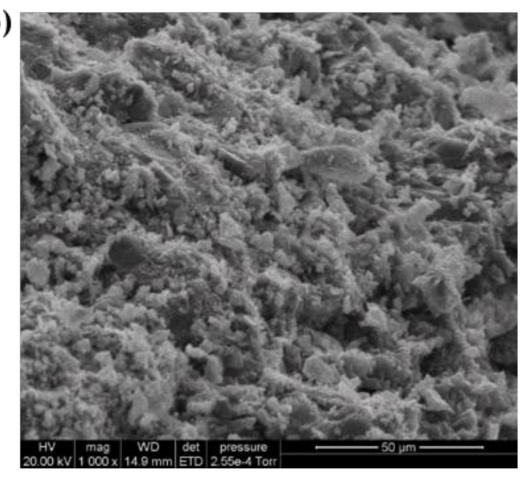

Figure 5. ESEM images of the G1 (a) and G2 (b) matrices.

Table 6. Atomic composition of the G1 and G2 matrices (the data were obtained by EDX determinations and represent the average of five measurements in different samples' positions).

\begin{tabular}{ccccccc}
\hline \multirow{2}{*}{ Sample } & $\mathbf{7}$ Element Atomic \% \\
\cline { 2 - 7 } & $\mathbf{O}$ & $\mathbf{M g}$ & $\mathbf{A 1}$ & $\mathbf{S i}$ & $\mathbf{K}$ & $\mathbf{C a}$ \\
\hline G1 & 66.1 & 1.1 & 7.7 & 12.9 & 5.4 & 6.8 \\
G2 & 66.7 & 0.6 & 5.5 & 21.2 & 3.2 & 2.8 \\
\hline
\end{tabular}

The FTIR spectra of the matrices (Figure 6) show the presence of relatively broad signals centered at 1040, 860, and $450 \mathrm{~cm}^{-1}$ (the asterisks in Figure 6), characteristic of the aluminosilicate structure [61]. In the G2 matrix, the sharp absorptions at 795, 777 and $690 \mathrm{~cm}^{-1}$ of quartz (the circles in Figure 6) are also visible [62]. 


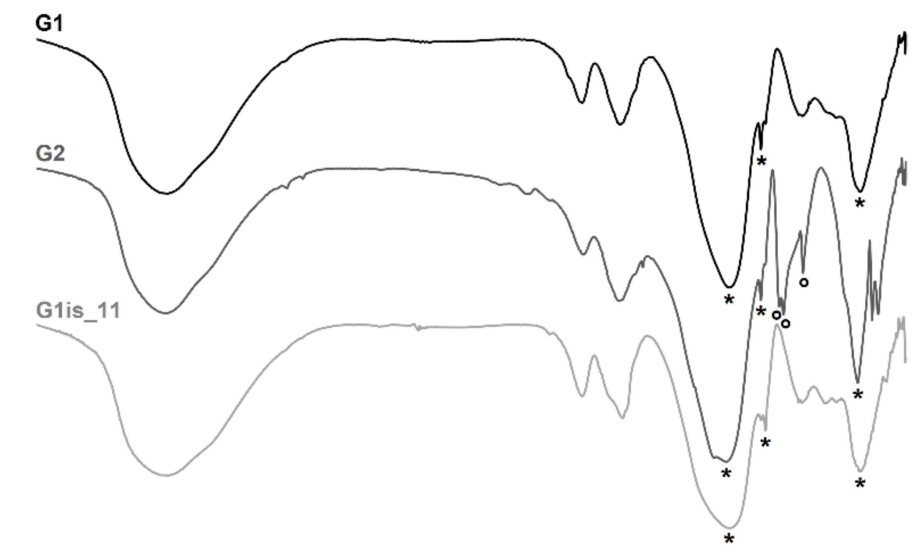

$\begin{array}{llllllllllllllll}4000 & 3750 & 3500 & 3250 & 3000 & 2750 & 2500 & 2250 & 2000 & 1750 & 1500 & 1250 & 1000 & 750 & 500 & 250\end{array}$ wavenumber $\left(\mathrm{cm}^{-1}\right)$

Figure 6. FTIR spectra of the G1, G2 matrices and of G1is_11 $\left(^{*}=\right.$ signals relative to aluminosilicates; $\circ=$ signals due to quartz).

The Raman spectra (Figure 7) show for both matrices the weak broad signals at $530 \mathrm{~cm}^{-1}$ of the Q2 Si-O-Si system and at $650 \mathrm{~cm}^{-1}$ of the calcium silicate hydrate, together with a weak, narrowband at $797 \mathrm{~cm}^{-1}$ due to $\mathrm{SiO}_{4}{ }^{4-}$ groups (the asterisks in Figure 7). Absorptions at $1085 \mathrm{~cm}^{-1}$ due to the O-C-O symmetric stretching of $\mathrm{CaCO}_{3}$ precipitate as calcite are accompanied in the case of G2 by strong absorptions at 464, 205, and $127 \mathrm{~cm}^{-1}$ (the circles in Figure 7) due to quartz [63].

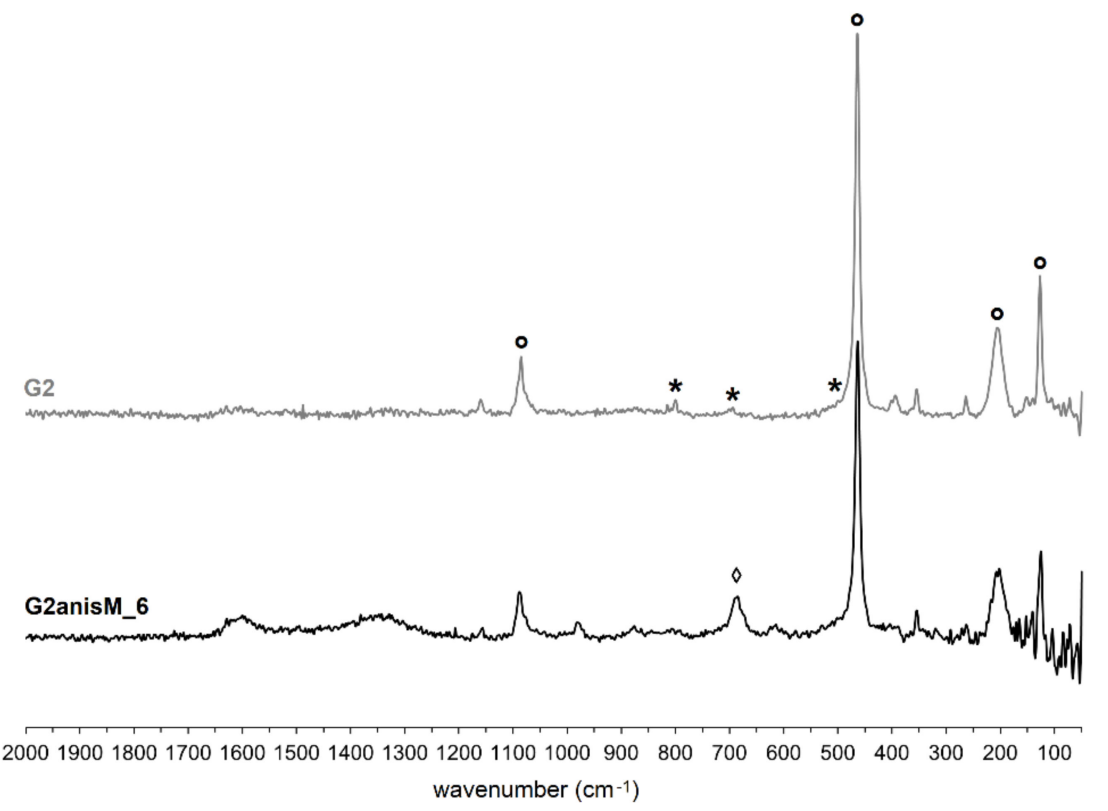

Figure 7. Raman spectra of G2 matrix and of G2anisM_6. ( ${ }^{*}=$ peaks relative to $\mathrm{SiO}_{4}{ }^{4-}$ groups; $\circ=$ peaks due to quartz; $\diamond=$ peak at $688 \mathrm{~cm}^{-1}$ due to anis-SrFe $\left.{ }_{12} \mathrm{O}_{19}\right)$.

MAS-NMR spectroscopic studies conducted on the ${ }^{27} \mathrm{Al}$ and ${ }^{29} \mathrm{Si}$ nuclei have been essential to defining the type of geopolymeric matrix obtained $[64,65]$.

${ }^{27} \mathrm{Al}$ MAS-NMR of the well-shaped signal of the geopolymers G1 and G2 at around $+58.2 \mathrm{ppm}$ has been associated with tetrahedral aluminum [66] with the almost complete transformation of the kaolinitic and gehlenite slag phases in the Ca-based geopolymer matrix $[67,68]$, suggesting three-dimensional networking of the type AlQ4(4Si) (Figure 8). 


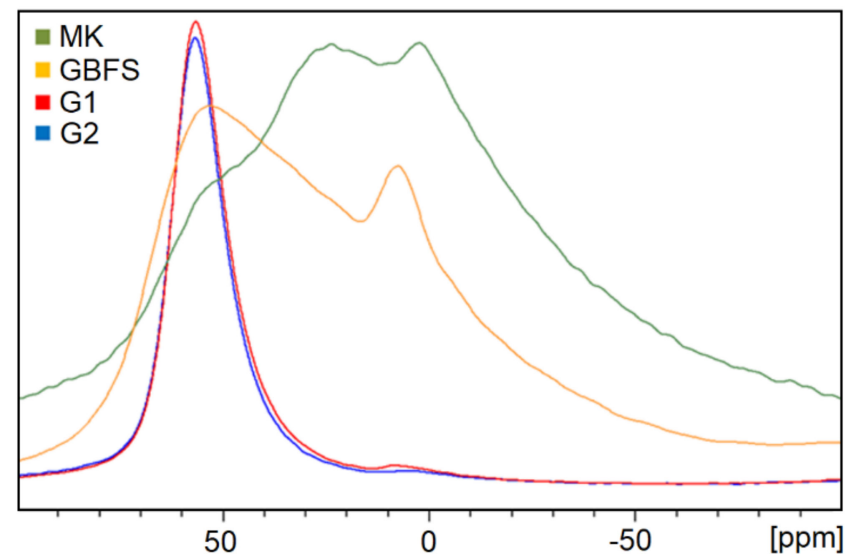

Figure 8. ${ }^{27} \mathrm{Al}$ MAS-NMR of matrices G1 and G2 compared with metakaolin (MK) and groundgranulated blast-furnace slag (GBFS).

As for the ${ }^{29}$ Si MAS-NMR spectra of G1 and G2, the reaction of MK and GBFS with alkaline silicate solution produced a broad peak centered at $-87.4 \mathrm{ppm}$ (Figure 9) for both matrices that are indicative of the new geopolymer matrix formed.

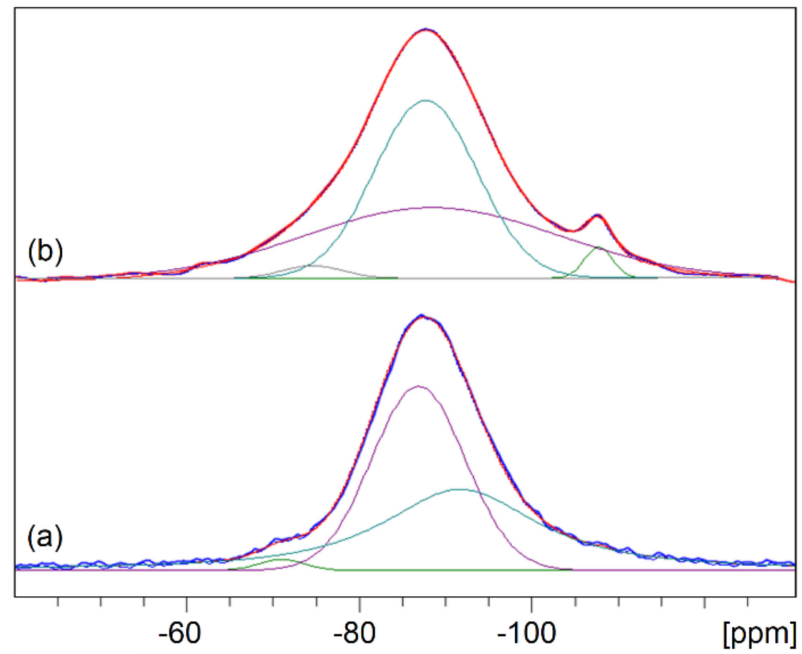

Figure 9. ${ }^{29}$ Si MAS-NMR of G1 matrix (a), G2 matrix (b) with deconvolved components.

In the presence of metakaolin, an aluminosilicate network dominates the reaction creating cyclic structures that were analyzed deconvolving the spectra to show the components forming the broad peak. In G1, the tall peak at $-91.26 \mathrm{ppm}$ could be attributed to the new $\mathrm{Q} 4(3 \mathrm{Al})$ and at $-86.6 \mathrm{ppm}$ to the $\mathrm{Q} 4(4 \mathrm{Al})$ aluminosilicate network. In $\mathrm{G} 2$, the Gaussian symmetric peaks at $-87.3 /-88.0 \mathrm{ppm}$ show an undetermined presence of both aluminosilicate networks. At -71.6 and $-74.5 \mathrm{ppm}$ for the two matrices and at $-106.8 \mathrm{ppm}$ for quartz in G2, the unreacted GBFS contributions are visible.

In both the XRD patterns of the matrices (Figure 10), a very broad hump between 20 and $40^{\circ}$, characteristic of amorphous materials, is visible. The XRD diffractograms show the same mineralogical phases, but G1 contains only small traces of vaterite, and G2 contains much more than G1 [13].

The TG-DTA measurements of the geopolymer matrices (Figure 11) reveal a total water content of $15.1 \%$ and $7.5 \%$, respectively, and an asymmetric mass-loss peak in the $50-230{ }^{\circ} \mathrm{C}$ temperature range. A broad endothermic peak in the DTA curve centered at about $132{ }^{\circ} \mathrm{C}$ (G1) and $112{ }^{\circ} \mathrm{C}(\mathrm{G} 2)$, extending for both to about $225^{\circ} \mathrm{C}$, corresponds to a weight loss of $8.5 \%$ for G1 and $4.2 \%$ for G2 associated with free or "interstitial" water loss [69,70]. In the range, $225-510{ }^{\circ} \mathrm{C}$, a total water loss of $3.8 \%$ and $1.7 \%$ for G1 and G2, respectively, 
continuous and featureless, was associated with bound water and dihydroxylation of hydroxyl groups. In the range, $510-715^{\circ} \mathrm{C}$, the amount of hydroxyl lost $(2.6 \%$ and $1.5 \%)$ is more similar in the two matrices than that lost in the range $30-510{ }^{\circ} \mathrm{C}$, indicating that the higher quantity of water used in the synthesis of G1 respect to G2 remained mainly interstitial. Above $725^{\circ} \mathrm{C}$, no additional mass loss occurs with no sintering/melting events to $1200{ }^{\circ} \mathrm{C}$. The endothermic peak of G2 DTA at $574{ }^{\circ} \mathrm{C}$ is in agreement with phase changing of quartz, while the broad exothermic peak at about $1000{ }^{\circ} \mathrm{C}$ indicates in both samples that the residual unreacted metakaolin crystallized into mullite [71].

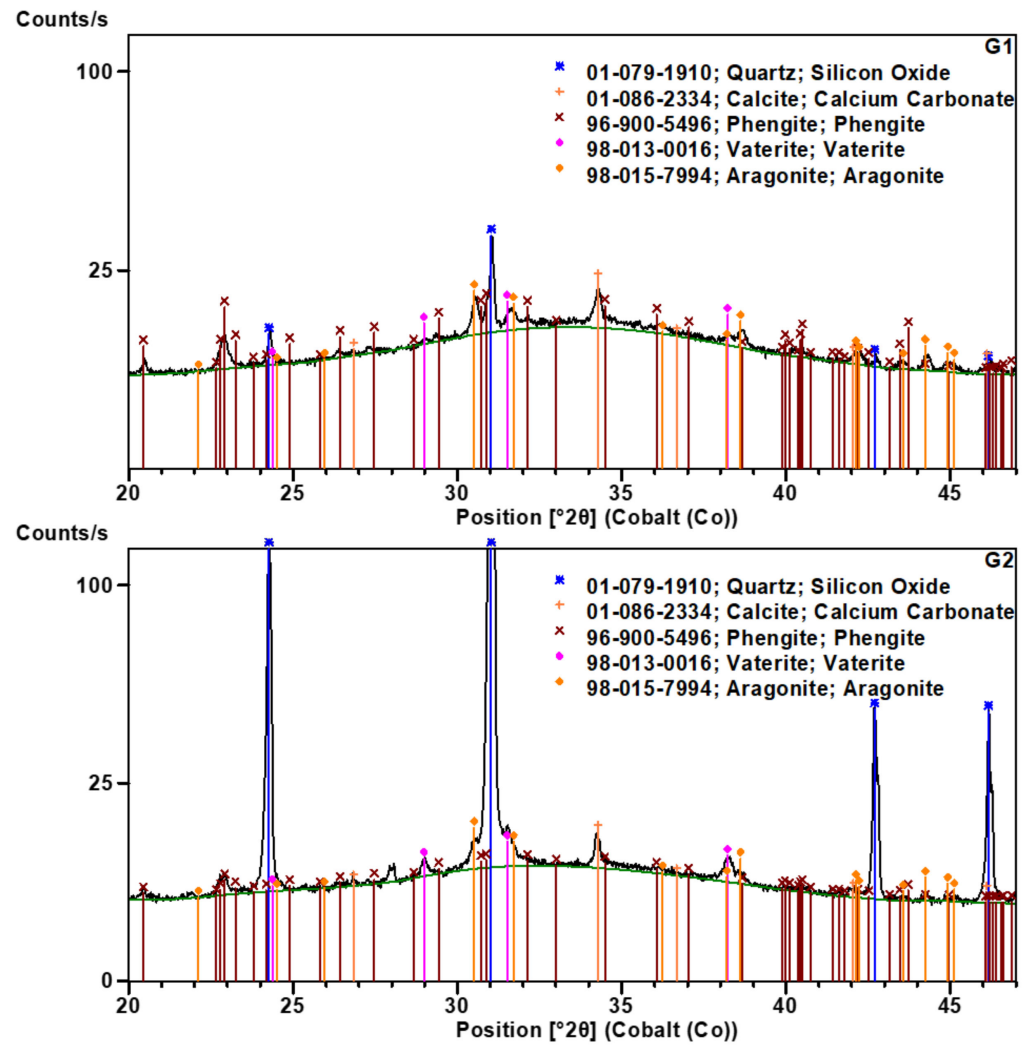

Figure 10. XRD patterns of the G1 and G2 matrices.

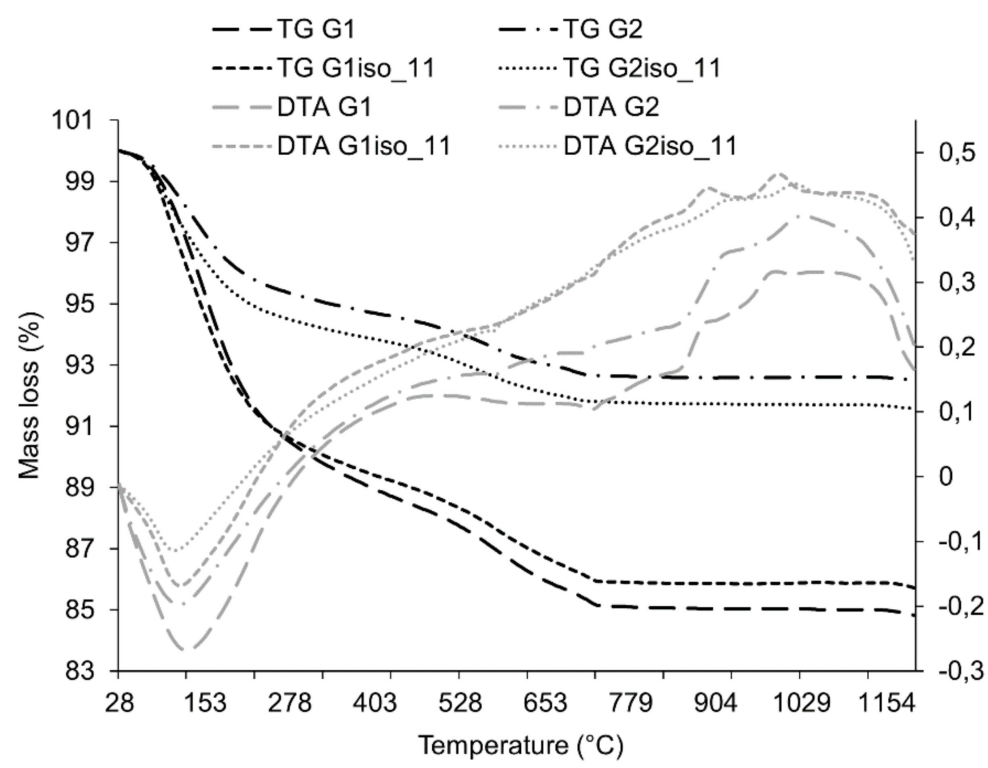

Figure 11. TG-DTA curves of the geopolymeric matrices G1 and G2. 


\subsection{Structural and Morphological Study of the Magnetic Inorganic Composites}

3.3.1. Morphology and Thermal Behavior

The density of G1 $\left(2.02 \mathrm{~g} / \mathrm{cm}^{3}\right)$ was lower than G2 $\left(2.29 \mathrm{~g} / \mathrm{cm}^{3}\right)$ due to the different amounts of water added and increased in the presence of the magnetic particles.

In Figure 12, some selected ESEM images of the magnetic composites show the porosity of the materials, with apparently no influence of the geopolymerization carried out under magnetic conditions. The image in Figure 13a of G2anisM_6, detected using backscattered electrons (thus, the embedded magnetic particles appear to be lighter concerning the surrounding matrix), shows that the particles have the tendency to form aggregates. It is to note that in the case of G2anisM_6, the magnetic particles give rise to stacks (Figure 13a), otherwise in the G2anis_6 sample, particles tend to clump together (Figure 13b).
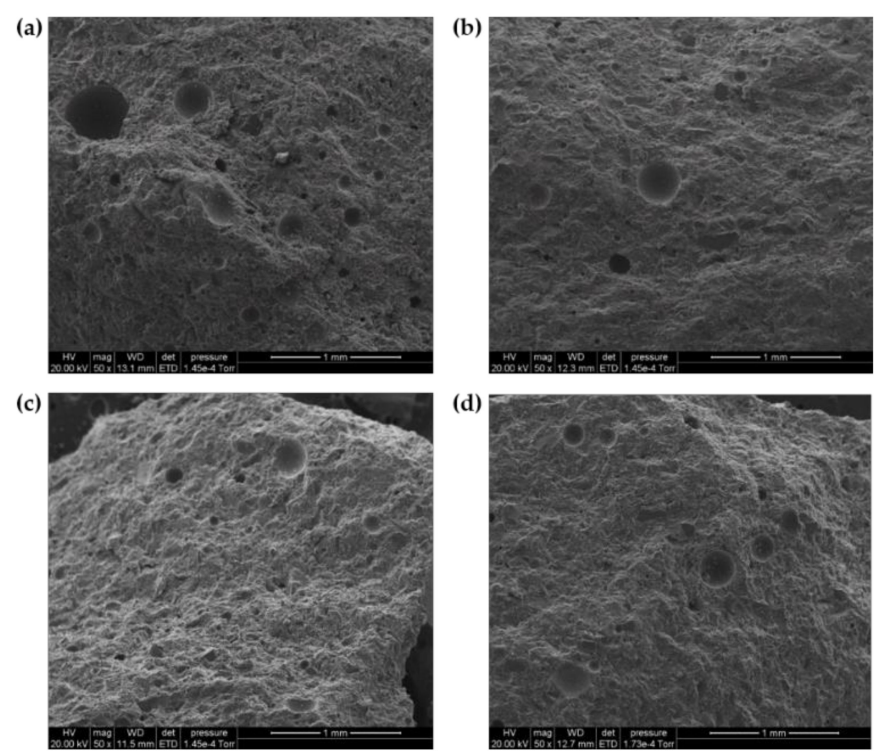

Figure 12. Selected ESEM images of G2anis_6 (a), G2anisM_6 (b), G2is_6 (c) and G2isM_6 (d).
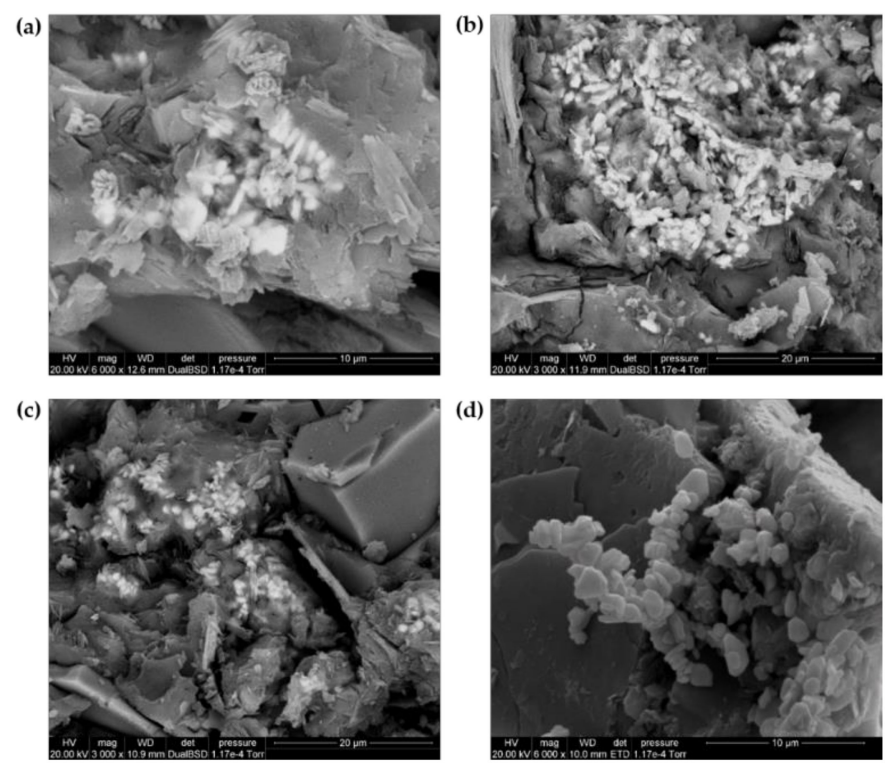

Figure 13. Selected ESEM images of magnetic particles aggregate in G2anis_6 (a), G2anisM_6 (b), G2is_6 (c) and G2isM_6 (d).

Magnetic particles also aggregate in the G2isM_6 sample (Figure 13c), but in a lower extent, giving rise to smaller aggregates (typically $20 \times 20 \mu \mathrm{m}$ for is- $\mathrm{SrFe}_{12} \mathrm{O}_{19}$ vs. $30 \times 30 \mu \mathrm{m}$ 
for anis-SrFe ${ }_{12} \mathrm{O}_{19}$, in the presence of the same amount of ferrite, in more distributed shape) and appear to be more distributed in the case of G2is_6, where rare, ordered aggregates can be detected (Figure 13d).

As observed in Figure 11, the TG-DTA curves of the two matrices concerning the composites G1iso_11 and G2iso_11 show an overlapping trend.

\subsubsection{FTIR, Raman and XRD Characterization of the Magnetic Geopolymers}

In the FTIR of the composites, the signals of the $\mathrm{SrFe}_{12} \mathrm{O}_{19}$ at 552 and $601 \mathrm{~cm}^{-1}$ are evident, in particular, in the G1 derivatives, while the absorption at 650 and $540 \mathrm{~cm}^{-1}$ are masked by the signals of the matrix (Figure 6).

The Raman spectra of the composites do not differ from the corresponding matrices. A sharpening of the peaks in the samples containing anis- $\mathrm{SrFe}_{12} \mathrm{O}_{19}$ polymerized under magnetic field and the presence of a peak at $688 \mathrm{~cm}^{-1}$, which is the most intense peak of the ferrite [44], can be observed (Figure 7).

In Figure 14, the XRD diffractograms of G1is_11 and G1isM_11, in the $2 \theta$ range from $35^{\circ}$ up to $44^{\circ}$ are reported together with those of G2anis_6 and G2anisM_6, where the two main peaks of ferrites are labeled with the corresponding measured d-spacings. The peaks of $\mathrm{SrFe}_{12} \mathrm{O}_{19}$ and $\mathrm{Ba} 0.98 \mathrm{Fe} 11.93 \mathrm{O} 18.84$ coincide with the d-spacings of their relative reference patterns 98-018 4961 and 98-008-7406 (Panalytical ICSD database) even after the geopolymerization process and the peaks broadening (FWHM) shows no significant variation. This means that the process affects neither the ferrites' structures nor their crystallite sizes and/or microstrain (which is related to the peak broadening).

\subsubsection{Magnetic Characterization}

The saturation magnetization $\mathrm{M}_{\mathrm{S}}$ was measured at $\mathrm{T}=300 \mathrm{~K}$ in all the prepared geopolymer samples. By calculating the ratio between the $\mathrm{M}_{\mathrm{S}}$ values of the sample and of the starting $\mathrm{Sr}$ ferrite particles, the mass concentration of the magnetic particles was evaluated. We found that, in all the samples, the concentration of magnetic particles was in agreement with the nominal one reported in Table 2, within the error. As this result turned out to be independent of the specific matrix, in Table 7, the data corresponding to four representative samples are reported.

Table 7. Magnetic data relative to the composite geopolymer samples, labeled as in column 1.

\begin{tabular}{|c|c|c|c|c|c|}
\hline Sample & $\begin{array}{c}\mathrm{M}_{\mathrm{S}}(\mathrm{emu} / \mathrm{g})^{1} \\
\mathrm{~T}=300 \mathrm{~K} \\
\quad \pm 2 \%\end{array}$ & $\begin{array}{c}\mathrm{M}_{\mathrm{S}}(\mathrm{emu} / \mathrm{g})^{2} \\
\mathrm{~T}=20 \mathrm{~K} \\
\quad \pm 2 \%\end{array}$ & $\begin{array}{l}\text { Magnetic } \\
\text { Particles } \\
\text { (\% weight) } \\
\quad \pm \mathbf{3} \%\end{array}$ & $\begin{array}{c}\mathrm{H}_{\mathrm{C}}(\mathrm{kOe})^{3} \\
\mathrm{~T}=300 \mathrm{~K} \\
\quad \pm \mathbf{1 \%}\end{array}$ & $\begin{aligned} & \mathbf{M}_{\mathbf{R}}{ }^{4} \\
& \mathrm{~T}=300 \mathrm{~K} \\
& \pm 2 \%\end{aligned}$ \\
\hline G2anis_6 & 4.4 & 6.5 & 5.9 & 2.82 & 0.45 \\
\hline G2is_6 & 4.3 & 6.1 & 6.2 & 2.83 & 0.45 \\
\hline G1anis_11 & 7.8 & 11.6 & 10.4 & 3.68 & 0.45 \\
\hline G1is_11 & 7.0 & 10.3 & 10.1 & 2.90 & 0.44 \\
\hline
\end{tabular}

$\overline{{ }^{1} \text { saturation magnetization at } 300 \mathrm{~K}^{2}{ }^{2} \text { saturation magnetization at } 20 \mathrm{~K} ;{ }^{3} \text { coercivity at } 300 \mathrm{~K} ;{ }^{4} \text { squareness }}$ parameter at $300 \mathrm{~K}$. 


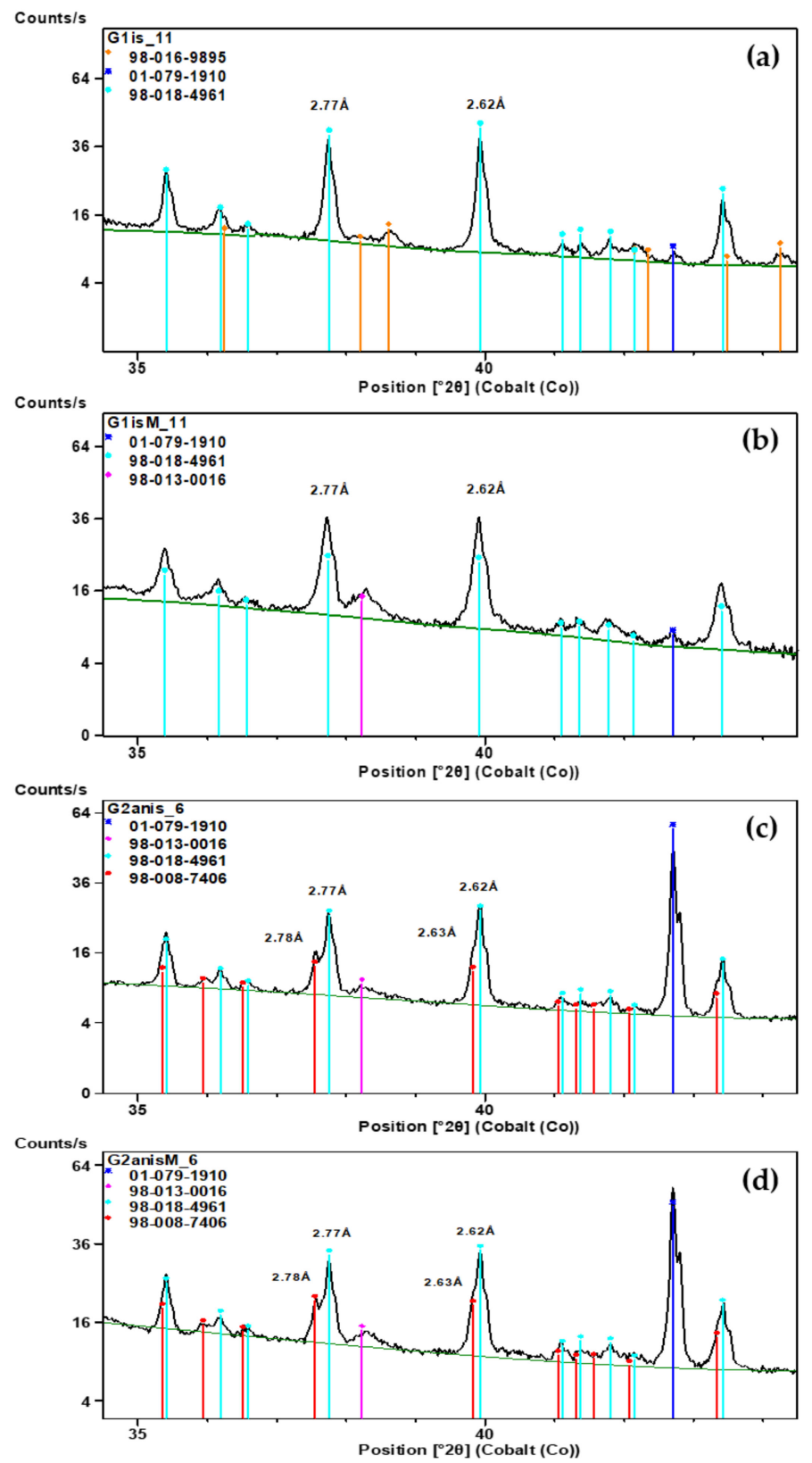

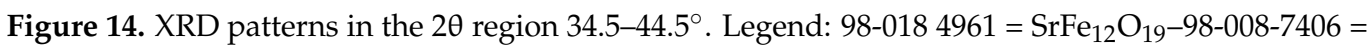
$\mathrm{Ba}_{0.98} \mathrm{Fe}_{11.93} \mathrm{O}_{18.84}-01-079-1910$ = quartz-98-013-0016 = vaterite-98-016-9895 = aragonite; (a) G1is_11, FWHM of is-SrFe ${ }_{12} \mathrm{O}_{19}$ main peak $=0.11^{\circ} 2 \theta$; (b) G1isM_11, FWHM of $\mathrm{SrFe}_{12} \mathrm{O}_{19}$ main peak $=0.12^{\circ}$ $2 \theta$; (c) G2anis_6 FWHM of $\mathrm{SrFe}_{12} \mathrm{O}_{19}$ main peak $=0.09^{\circ} 2 \theta-\mathrm{FWHM}$ of $\mathrm{Ba}_{0.98} \mathrm{Fe}_{11.93} \mathrm{O}_{18.84}$ main peak $=0.10^{\circ} 2 \theta$; (d) G2anisM_6 FWHM of $\mathrm{SrFe}_{12} \mathrm{O}_{19}$ main peak $=0.10^{\circ} 2 \theta-\mathrm{FWHM}_{\text {of }} \mathrm{Ba}_{0.98} \mathrm{Fe}_{11.93} \mathrm{O}_{18.84}$ main peak $=0.11^{\circ} 2 \theta$.

On these samples, we also have measured $\mathrm{M}_{\mathrm{S}}$ at $\mathrm{T}=20 \mathrm{~K}$ (Table 7). The ratio between the $\mathrm{M}_{\mathrm{S}}$ measured at $300 \mathrm{~K}$ and at $20 \mathrm{~K}$ is consistent, within the error, with that calculated for the starting magnetic particles. Hence, the incorporation of the particles in the geopolymer matrix did not affect the magnetization and its thermal dependence, which means that there was no interdiffusion between the magnetic and geopolymeric phases.

In Figure 15a, the magnetic hysteresis loops at $\mathrm{T}=300 \mathrm{~K}$ of the four selected samples are shown; they are normalized to their $M_{S}$ values to better compare their shapes. The loops are similar and appear almost superposed. The wasp-waist-like shape, characterizing the loops of the starting magnetic particles (Figure 4), is no more visible. This indicates that a different magnetic arrangement of the particles and possibly a different state of 
magnetic interaction was obtained concerning the starting ones, namely that the existence of large agglomerates that substantially reproduce the behavior of the non-dispersed starting particles can be excluded. The $\mathrm{M}_{R}$ values are very close in all the samples, slightly smaller than 0.5 (Table 7), which reveals that a random spatial orientation of the magnetic particles in the geopolymer matrix, both isotropic and anisotropic, was attained during the synthetic process. Moreover, $\mathrm{H}_{\mathrm{C}}$ is higher in the composite samples compared to the starting particles, which is consistent with a reduction of the strength of the magnetic interactions between the particles after being dispersed in the geopolymer matrix, namely with an increased inter-distance. Hence, the analysis of the magnetic loops indicates that a good dispersion of the particles in the matrix was obtained.
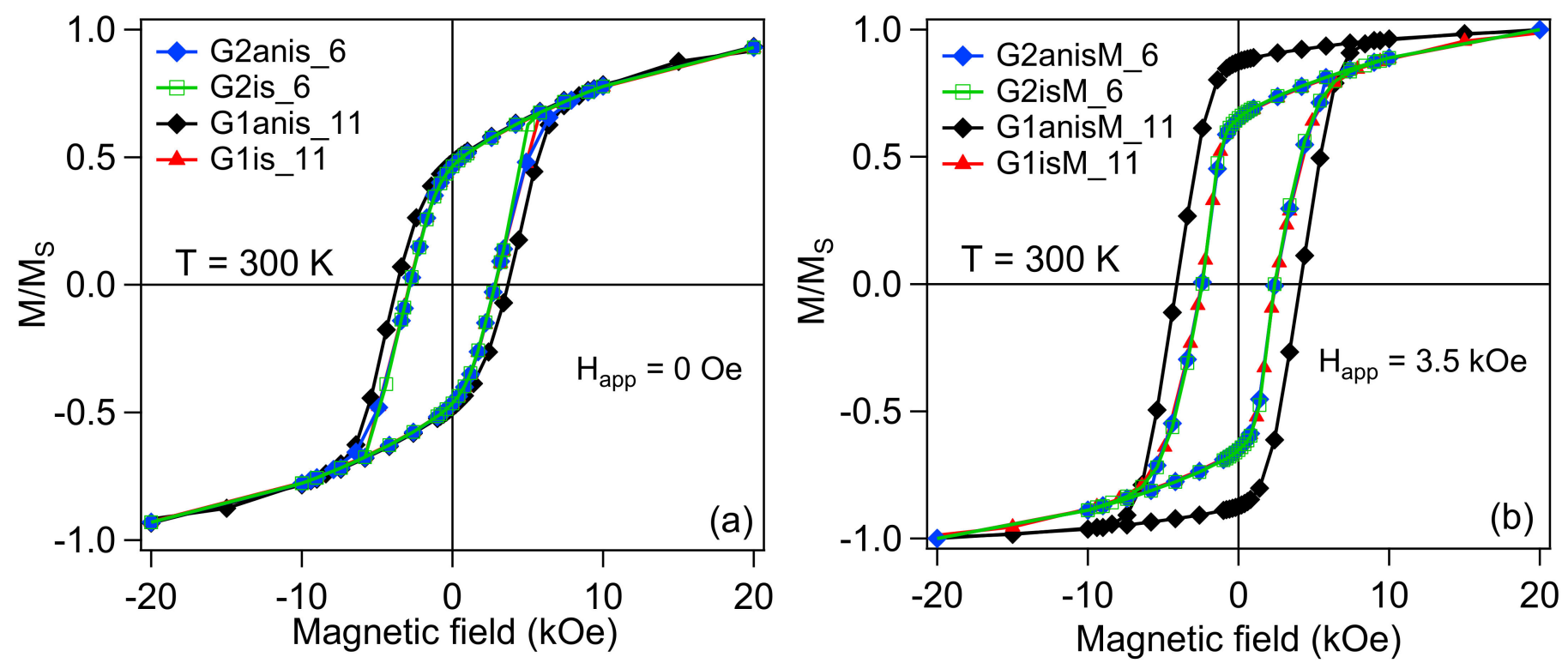

Figure 15. Magnetic hysteresis loops measured at $\mathrm{T}=300 \mathrm{~K}$ on the indicated composite samples produced with no $\mathrm{H}_{\mathrm{APP}}(\mathbf{a})$ and with $\mathrm{H}_{\mathrm{APP}}=3.5 \mathrm{kOe}(\mathbf{b})$. The loops are normalized to their $\mathrm{M}_{\mathrm{S}}$ value.

Magnetic hysteresis loops have also been measured at $\mathrm{T}=300 \mathrm{~K}$ on geopolymer samples with compositional properties similar to those of the four selected ones addressed above but prepared in $\mathrm{H}_{\mathrm{APP}}=3.5 \mathrm{kOe}$. In particular, the measurements were carried out with the magnetic field along the same direction of $\mathrm{H}_{\mathrm{APP}}$. The results are shown in Figure 15b. The loops are more squared than those in Figure 15a relative to the samples prepared in $\mathrm{H}_{\mathrm{APP}}=0$. In fact, $\mathrm{M}_{\mathrm{R}}$ is larger than 0.5 in all the samples (Table 8).

Table 8. Magnetic data relative to the composite geopolymer samples, labeled as in column 1, prepared in the presence of a magnetic field $\mathrm{H}_{\mathrm{app}}$ during the curing process.

\begin{tabular}{|c|c|c|}
\hline Sample & $\mathrm{H}_{\mathrm{C}}(\mathrm{kOe})^{1} \pm 1 \%$ & $\mathbf{M}_{\mathbf{R}}{ }^{2} \pm 2 \%$ \\
\hline G2anisM_6 & 2.42 & 0.59 \\
\hline G2isM_6 & 2.40 & 0.60 \\
\hline G1anisM_11 & 4.10 & 0.84 \\
\hline G1isM_11 & 2.47 & 0.59 \\
\hline
\end{tabular}

${ }_{1}^{1}$ coercivity; ${ }^{2}$ squareness parameter.

This is explained considering that $\mathrm{H}_{\mathrm{APP}}$, applied when the $\mathrm{Sr}$ ferrite particles were dispersed in the liquid matrix before solidification, activated two different magnetizing mechanisms: it magnetized, mainly through the movement of the domain walls, the particles to a certain extent so that each acquired a net magnetic moment; it exerted a torque acting on the magnetic moments resulting in the physical rotation of the particles themselves [72]. Therefore, a high degree of alignment of the magnetic moments of the Sr-ferrite 
particles, both anisotropic and isotropic, was obtained. When the geopolymeric matrix solidified, and $\mathrm{H}_{\mathrm{APP}}$ was removed, the remanent moments of the particles maintained their preferential alignment, parallel to $\mathrm{H}_{\mathrm{APP}}$.

This has resulted in higher $\mathrm{M}_{\mathrm{R}}$ values compared to those measured in the samples solidified without $\mathrm{H}_{\mathrm{APP}}$. In particular, the highest $\mathrm{M}_{\mathrm{R}}=0.84$ was measured in G1anisM_11 (Figure 16), while $\mathrm{M}_{\mathrm{R}}=0.6$ in the other samples (experimental error $2 \%$ ). Similarly, the $\mathrm{H}_{\mathrm{C}}$ parameter (Table 8$)$ is almost the same in all the samples $\left(\mathrm{H}_{\mathrm{C}} \sim 2.4 \mathrm{kOe}\right)$, except in G1anisM_11, where it reaches the highest value of $4.10 \mathrm{kOe}$. Both results indicate that a better alignment of the remanent moments was achieved in the case of anisotropic particles dispersed in the matrix at high concentration, whereas substantially similar configurations were attained in the other samples. To account for this effect, it is to be considered that the particles, when magnetized by $\mathrm{H}_{\mathrm{APP}}$, produced an internal magnetic field (i.e., Lorentz field [46]), which added to $\mathrm{H}_{\mathrm{APP}}$, parallel to it. The anisotropic particles, larger and with higher $\mathrm{M}_{\mathrm{S}}$ than the isotropic ones, acquired larger moments and were more easily rotated by $\mathrm{H}_{\mathrm{APP}}$, thus producing a more intense internal field. This mechanism, together with the high concentration of anisotropic particles present in G1anisM_11, gave rise to an internal field strong enough to determine a substantial improvement in the alignment of the magnetic moments compared to the other investigated samples.

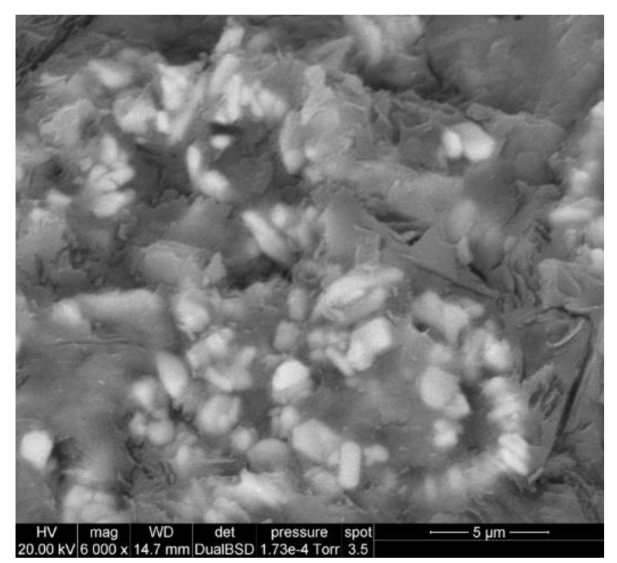

Figure 16. Selected ESEM image of magnetic particles aggregates in G1anisM_11.

\subsubsection{Electrical Characterization}

To shed light on the interaction of the composite geopolymer with electromagnetic fields, its electrical impedance was measured. The AC impedance spectra (Nyquist plots), carried out on the samples listed in Table 3, recorded about 1 year from sample preparation, are shown in Figure 17 by plotting the imaginary part of the impedance Z, Zim, versus the real one, Zre.

In the plots, the high-frequency arcs are well outlined. In all cases, the arc center is depressed below the real axis, which is due to the relaxation of polarization processes within the material and results in dielectric dispersion, i.e., a decrease of the capacitance when increasing the frequency [73]. The depression angle is in the range of $23-27^{\circ}$ for the four plots reported.

From the plots, the values of the "bulk resistance" corresponding to the real part of impedance at where the high and low-frequency arcs met and of the "relaxation frequency" corresponding to the top point of the high-frequency arc can be achieved.

By considering the measured sample dimensions, the bulk resistivity can be calculated. In Figure 18a, the plot values of bulk resistivity versus the samples' Ksil content are reported. In Figure 18b, the relaxation frequency is plotted versus Ksil content. The potassium silicate activator (Ksil) concentration in Figure 18 is reported in terms of the weight $\%$ with respect to the initial weight, which is the weight of all the reagents, including any added extra water. 

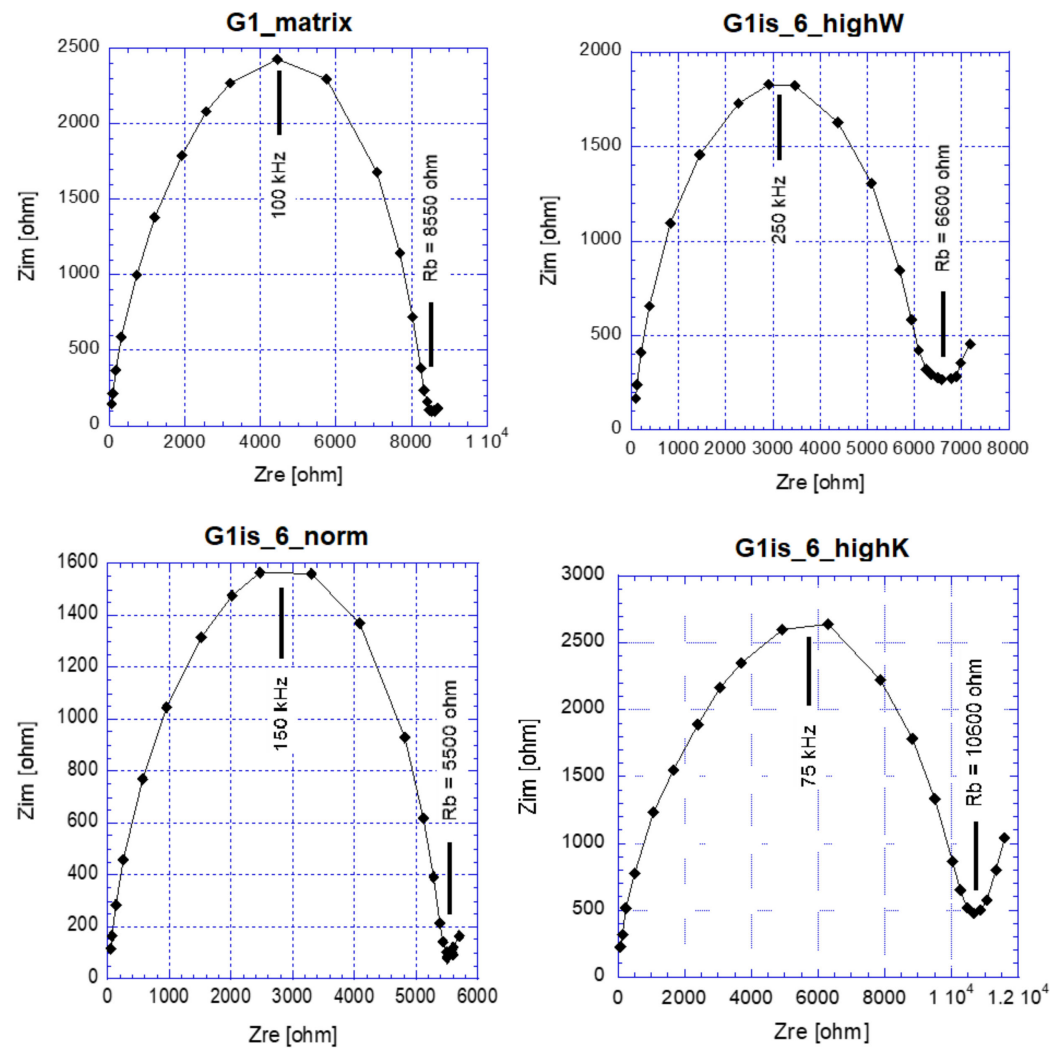

Figure 17. Nyquist plots of disk samples of G1_matrix, G1is_highW, G1is_highK and G1is_norm.
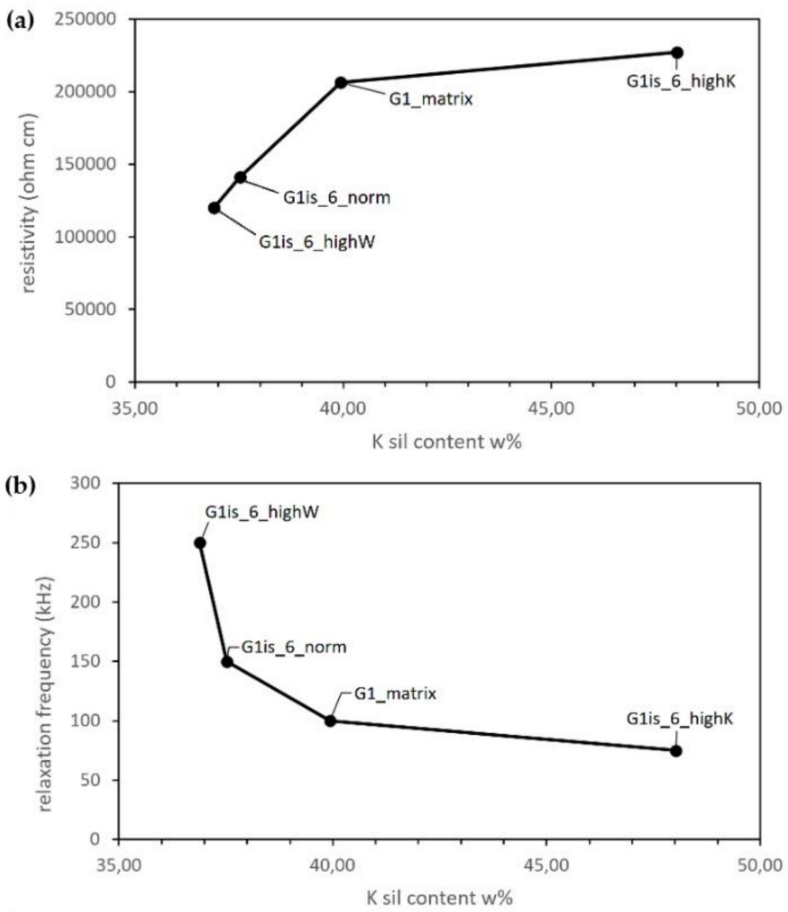

Figure 18. Bulk resistivity (a) and relaxation frequency (b) vs. Ksil content expressed in weight\% with respect to the initial weight.

In Figure 18a, an increase of resistivity with increasing Ksil content is shown: this behavior can be explained by the fact that for geopolymer formulations, in general, exists an optimum concentration of the activator to reach the best mechanical performances, which occur when the concentration of alkali activator ions $\left(\mathrm{K}^{+}\right.$in our case) equals the concentra- 
tion of $\mathrm{Al}^{3+}$ ions of the aluminum-silicate network of the forming geopolymer [16]. The presence of $\mathrm{K}^{+}$excess leaves unreacted activator that eventually carbonates and can lead to a decrease in mechanical properties due to incomplete geopolymerization. However, due to the particular nature of the samples, which were prepared with the lowest possible fluidity to avoid magnetic powder aggregation, different levels of geopolymerization (depending on activator and water amounts) can be achieved. Since electrical resistivity of geopolymers is known to increase with geopolymerization [74], incomplete geopolymerization is expected to yield a lower electrical resistivity as is observed in G1is_6_norm, which contains a similar concentration of Ksil as the matrix, but under low fluidity under adverse mixing conditions. In sample G1is_6_highK, the higher concentration of Ksil contributes to better geopolymerization both directly via a higher dissolution rate of the MK and slag reagents and indirectly due to a slightly better fluidity coming from the liquid part of the Ksil, thus compensating for the adverse mixing conditions, resulting in a sample with electrical resistivity slightly higher than the matrix. For the sample G1is_6_highW in which fluidity and mixing conditions were improved via extra water addition, reactivity and geopolymerization should be similar to the matrix, even if the extra water addition increases sample porosity, which is known to decrease electrical resistivity $[75,76]$, in agreement with the lower resistivity observed for sample G1is_6_highW.

Figure 18b shows the so-called "relaxation frequency" as a function of Ksil concentration. Relaxation frequency is related to the double-layer capacitance of the sample associated with the solid/pore solution interfaces in the sample. In analogy to concrete and mortar samples, a lower relaxation frequency indicates a higher level of polymerization [75]. Hence the observed trend of relaxation frequency confirms an increased geopolymerization with increasing Ksil concentration in our samples.

Concerning the available literature, conductivity values for geopolymers span a wide range, depending on the reagents used and preparation conditions. For example, conductivity values reported in. [76] for Nasil-blast furnace slag samples aged 30 days are $0.02-0.05 \mathrm{~S} / \mathrm{m}$, while in. [77] for Mk-Nasil geopolymer samples, a value of $6.2 \cdot 10^{-3} \mathrm{~S} / \mathrm{m}$ can be retrieved based on reported sample dimensions and resistance values. In ref. [78], for geopolymer materials prepared using sodium silicate solutions and chemosynthetic $\mathrm{Al}_{2} \mathrm{O}_{3}-2 \mathrm{SiO}_{2}$ amorphous powders, a value of $1.5 \cdot 10^{-4} \mathrm{~S} / \mathrm{m}$ is reported. In comparison, our samples exhibit conductivities ranging from $4.4-8.3 \cdot 10^{-4} \mathrm{~S} / \mathrm{m}$, which is about 10-100 times lower than values reported in refs. [76,77] and 3-6 times higher than that of chemosynthetic geopolymers in [78]. Our highest value of resistivity $\left(2.3 \cdot 10^{5} \mathrm{ohm}-\mathrm{cm}\right.$, for G1is_6_highK) is in the same range as given by Davidovits, [13] suggesting a complete geopolymerization for this sample.

\subsection{Mechanical Properties}

The compressive strength data (Table 9) at 7 days of samples without quartz aggregates are reported in Figure 19, and a decrease with the increasing addition of magnetic powder can be noticed.

Table 9. Compressive strength data at 7 days for selected samples.

\begin{tabular}{lclc}
\hline Sample & Compressive Strength (MPa) & Sample & Compressive Strength (MPa) \\
\hline G1 & $58.5 \pm 5.7$ & G1anis_11 & $33.9 \pm 1.4$ \\
G2 & $46.8 \pm 0.5$ & G1is_11 & $36.2 \pm 2.7$ \\
G1anis_6 & $38.3 \pm 5.1$ & G2anis_6 & $49.9 \pm 3.3$ \\
G1is_6 & $44.8 \pm 1.5$ & G2is_6 & $56.4 \pm 1.0$ \\
G1anis_6DENSE & $57.55 \pm 1.87$ & G2anis_11 & $36.8 \pm 0.3$ \\
G1is_6DENSE & $61.5 \pm 2.6$ & G2is_11 & $47.7 \pm 2.8$ \\
\hline
\end{tabular}

Since the extra water addition was kept quite constant at 10\% for samples G1, G1_6, and G1_11 (both "is" and "anis"), the strength decrease must be associated directly with the magnetic particle addition. For samples G1_6DENSE, which were prepared with 
lower extra water than G1_6, higher compressive strength is observed, comparable to that of the matrix. Thus, in the DENSE samples, the negative effect of the presence of magnetic particles seems to be counterbalanced by the reduced amount of extra water used $(2.3-3.3 \%)$.

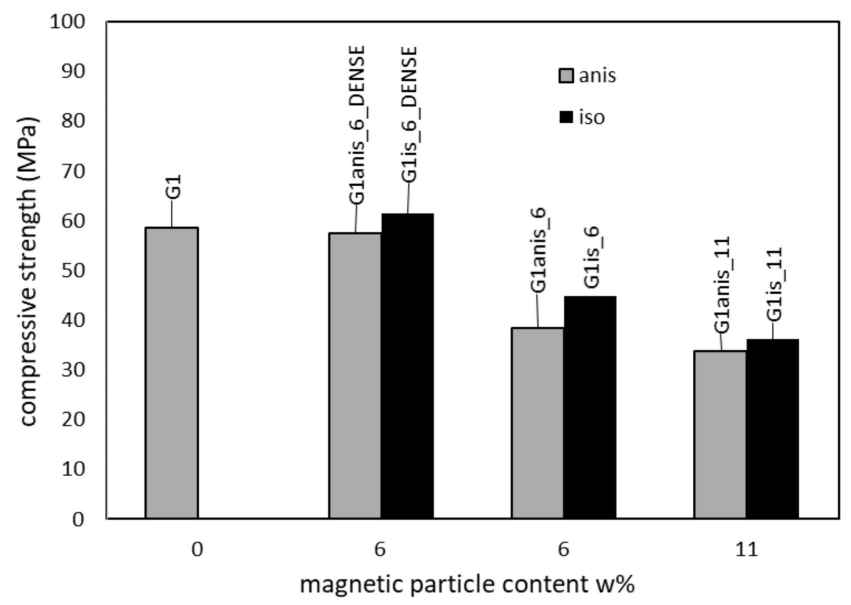

Figure 19. Compressive strength data for samples of series G1.

For the sample set G2, where quartz aggregates are added to the matrix to reduce the risk of aggregation of the magnetic particles, the compressive strength results shown in Figure 20 evidence an initial increase in strength as the magnetic powder was added to the quartz aggregates. As more magnetic particles are added, the strength decreases. This behavior can be explained by considering both as result of the presence of the magnetic particles and of the different amounts of extra water added during preparation. It is to note a slight difference between the values obtained when the isotropic particles are present, which are higher, concerning the anisotropic ones, reasonably due to a less inhomogeneous distribution of the magnetic particles inside the matrix, where larger anisotropic particles aggregates behave as places of fragility.

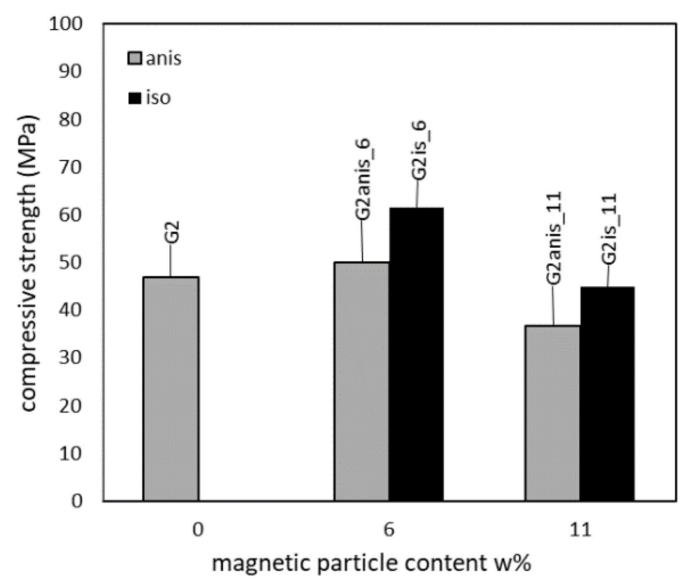

Figure 20. Compressive strength data for samples of series G2.

Comparing G1 and G2 series samples, two observations can be made: (1) A higher strength of matrix G1 is observed compared to matrix G2. This is reasonably due to the higher fluidity and thus better mixing conditions for matrix G1 due to the absence of aggregates, which promotes a higher degree of geopolymerization, as observed in the electrical measurements. (2) The strength difference between samples with isotropic and anisotropic magnetic powders is lower for G1 series samples compared to G2 series samples. As already noted, this strength difference is related to the different tendencies of clustering of the isotropic and anisotropic magnetic particles used. Since the addition of fine-grained 
quartz aggregates in G2 series samples was intended to reduce such magnetic particle clustering, the result appears surprising at first. However, it needs to be considered that the addition of fine quartz aggregates also has the side-effect of increasing the available surface area of aggregates to be infiltrated by the matrix. Therefore, less matrix is available to bind the additional magnetic particles, and any residual magnetic particle clusters will be weaker bonded in samples with quartz aggregates than in samples without. Hence, considering the different clustering tendencies of the isotropic and anisotropic particles used, the strength difference could well be amplified in samples with quartz aggregates if the dispersion were not effective enough.

It is noteworthy that the values of compressive strength here observed at 7 days resulted to be higher concerning those reported for high weight concretes bearing high content of magnetite $(<30 \mathrm{MPa})[7,14]$ and for $\mathrm{NdFeB} /$ cement composites [79].

\section{Conclusions}

A series of novel magnetic geopolymers were prepared, and many chemical, morphological and physical characterization data are collected to investigate the effect of the presence of $\mathrm{SrFe}_{12} \mathrm{O}_{19}$ particles.

The experimental procedure for preparation appears to be crucial to determine the morphology and the electrical properties of the final composites, in particular in terms of extra water amount and mixing. Thus, in principle, the preparation can be optimized even in the presence of higher amounts of magnetic particles, in terms of a suitable ratio between reactive components even in the presence of higher amounts of water necessary for good mixing.

The magnetic study has revealed that the $\mathrm{SrFe}_{12} \mathrm{O}_{19}$ magnetic particles can be relatively well dispersed in the inorganic matrix. A substantial increase in the remanent magnetization of the composite samples above the value achievable in the case of a random spatial distribution of the particles was obtained by embedding in the geopolymer $\mathrm{SrFe}_{12} \mathrm{O}_{19}$ anisotropic particles at high concentration, under the action of an external magnetic field during the solidification process.

The impedance measurements indicated that electrical resistance is mainly controlled by the chemical composition of the matrix as well as mixing conditions, yielding a maximum resistivity value (as shown by the diameters of the high-frequency arc in Nyquist plots) of $2.3 \cdot 10^{5} \mathrm{ohm} \mathrm{cm}$ for the sample G1is_6_highK, which is in the same range as given by Davidovits, [13] indicating for the sample a complete geopolymerization.

The collected data have demonstrated that new composites exhibit good mechanical properties (as compressive strength), higher with respect to those reported for high weight concretes with a high content of magnetite.

The work is ongoing with the objective to better control the final configuration of the magnetic particles into the inorganic matrix and to promote the participation of magnetic particles, suitably functionalized, to the buildup of the geopolymer matrix, to prepare materials with designed mechanical, magnetic and electrical properties.

The method could be of general application, considering the wide range of experimental parameters and modulability of the geopolymers preparation, together with the different types and amounts of magnetic particles, which could be introduced into the inorganic matrix, together with the fact that by using geopolymerization strategy exotic shapes to the final products could be achieved for a wide range of applications.

Supplementary Materials: The following are available online at https:/ / www.mdpi.com/article/10 .3390 / polym13081284/s1, Figure S1: Full-scale XRD profile of the G1 matrix, Figure S2: Full-scale XRD profile of the G2 matrix, Figure S3: Full-scale XRD profile of the isotropic $\mathrm{SrFe}_{12} \mathrm{O}_{19}$ particles, Figure S4: Full-scale XRD profile of the anisotropic $\mathrm{SrFe}_{12} \mathrm{O}_{19}$ particles, Figure S5: Full-scale XRD profile of the G1is_11 composite, Figure S6: Full-scale XRD profile of the G1isM_11 composite., Figure S7: Full-scale XRD profile of the G2anis_6 composite, Figure S8: Full-scale XRD profile of the G2anisM_6 composite. 
Author Contributions: Conceptualization, P.S.; R.B. and D.P.; methodology, P.S.; R.B.; D.D.; S.T.; M.N.; F.S.; L.D.B. and F.Z.; investigation, P.S.; R.B.; M.M.; D.D.; S.T.; M.N.; F.S.; L.D.B. and F.Z.; writing—original draft preparation, P.S.; R.B.; M.M.; D.D.; S.T.; M.N.; F.S.; L.D.B. and F.Z.; writingreview and editing, P.S.; R.B.; M.N.; F.S. and L.D.B.; supervision, P.S. and R.B.; project administration, P.S. and R.B.; funding acquisition, P.S. and R.B. All authors have read and agreed to the published version of the manuscript.

Funding: This research received no external funding.

Data Availability Statement: All the available data have been reported either in the manuscript or in the supporting materials.

Acknowledgments: P.S. wishes to thank the Department of Industrial Engineering (UNIPD-DII) BIRD2017 Project for financial support to the research activities. R.B. and M.M. wish to thank the Department of Industrial Engineering (UNIPD-DII) Twinning Program-2017 for financial support.

Conflicts of Interest: The authors declare no conflict of interest.

\section{References}

1. Magment: Concretes Wireless Power. Available online: https://www.magment.de (accessed on 12 March 2021).

2. Mansouri, I.; Nejat, M.; Shahbazi, S.; Karami, A. Effect of magnetite nanoparticles (ferroferric oxide) on discrete concrete properties. Constr. Mater. 2019, 172, 95-102. [CrossRef]

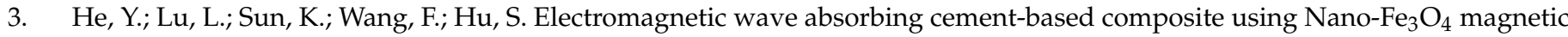
fluid as absorber. Cem. Concr. Compos. 2018, 92, 1-6. [CrossRef]

4. Wang, D.; Yang, P.; Hou, P.; Zhang, L.; Zhang, X.; Zhou, Z.; Xie, N.; Huang, S.; Cheng, X. Cement-based composites endowed with novel functions through controlling interface microstructure from $\mathrm{Fe}_{3} \mathrm{O}_{4} @ \mathrm{SiO}_{2}$ nanoparticles. Cem. Concr. Compos. 2017, 80, 268-276. [CrossRef]

5. Zhang, Y.; Hao, W.; Li, B.; Duan, Y.; Liu, S. Electromagnetic wave absorbing properties of double-layer cement composite and theory analysis. Asian J. Chem. 2014, 17, 5563-5566. [CrossRef]

6. Aygun, B.; Sakar, E.; Korkut, T.; Sayyed, M.I.; Karabulut, A. New high temperature resistant heavy concretes for fast neutron and gamma radiation shielding. Radiochim. Acta 2019, 107, 359-367. [CrossRef]

7. Valizadeh, A.; Aslani, F.; Asif, Z.; Roso, M. Development of heavyweight self-compacting concrete and ambient-cured heavyweight geopolymer concrete using magnetite aggregates. Materials 2019, 12, 1035-1060. [CrossRef] [PubMed]

8. Sikora, P.; Elrahman, M.A.; Horszczaruk, E.; Brzozowski, P.; Stephan, D. Incorporation of magnetite powder as a cement additive for improving thermal resistance and gamma-ray shielding properties of cement-based composites. Constr. Build. Mater. 2019, 204, 113-121. [CrossRef]

9. Florez, R.; Colorado, H.A.; Alajo, A.; Giraldo, C.H.C. The material characterization and gamma attenuation of Portland cement$\mathrm{Fe}_{3} \mathrm{O}_{4}$ composites for potential dry cask applications. Prog. Nucl. Energy 2019, 111, 65-73. [CrossRef]

10. Lou, Z.; Wang, Q.; Zhang, Y.; Zhou, X.; Li, R.; Liu, J.; Li, J. In-situ formation of low-dimensional, magnetic core-shell nanocrystal for electromagnetic dissipation. Compos. Part B 2021, 214, 108744. [CrossRef]

11. Jia, C.; Xia, T.; Ma, Y.; He, N.; Yu, Z.; Lou, Z.; Li, Y. Fe3O4/ $\alpha$-Fe decorated porous car-bon-based composites with adjustable electromagnetic wave absorption: Impedance matching and loading rate. J. Alloy. Compd. 2021, 858, 157706. [CrossRef]

12. Lou, Z.; Li, R.; Wang, P.; Zhang, Y.; Che, B.; Huang, C.; Wang, C.; Han, H.; Li, Y. Phenolic foam-derived magnetic carbon foams (MCFs) with tunable electromagnetic wave ad-sorption behavior. Chem. Eng. J. 2020, 391, 123571. [CrossRef]

13. Davidovits, J. Geopolymer Chemistry and Applications, 5th ed.; Institut Géopolymère: Saint-Quentin, France, 2008.

14. Mugahed Amran, Y.H.; Alyousef, R.; Alabduljabbar, H.; El-Zeadani, M. Clean production and properties of geopolymer concrete: A review. J. Clean. Prod. 2020, 251, 119679. [CrossRef]

15. Provis, J.L.; van Deventer, J.S.J. Geopolymers: Structures, Processing, Properties and Industrial Applications, 1st ed.; Woodhead Publishing Limited: Cambridge, UK, 2009.

16. Xie, T.; Visintin, P.; Zhao, X.; Gravina, R. Mix design and mechanical properties of geopolymer and alkali activated concrete: Review of the state-of-the-art and the development of a new unified approach. Constr. Build. Mater. 2020, 256, 119380. [CrossRef]

17. Wang, Y.S.; Alrefaei, Y.; Dai, J.G. Silico-aluminophosphate and alkali-aluminosilicate geopolymers: A comparative review. Front. Mater. 2019, 6, 106. [CrossRef]

18. Chen, W.; Zhu, Z. Utilization of fly ash to enhance ground waste concrete-based geopolymer. Adv. Mater. Sci. Eng. 2018, 4793917. [CrossRef]

19. Zhao, X.; Liu, C.; Wang, L.; Zuo, L.; Zhu, Q.; Ma, W. Physical and mechanical properties and micro characteristics of fly ash-based geopolymers incorporating soda residue. Cem. Concr. Compos. 2019, 98, 125-136. [CrossRef]

20. Sumesh, M.; Johnson Alengaram, U.; Jumaat, M.Z.; Mo, K.H.; Alnahhal, M.F. Incorporation of nano-materials in cement composite and geopolymer based paste and mortar-A review. Constr. Build. Mater. 2017, 148, 62-84. [CrossRef] 
21. Hua, P.; Sellaoui, L.; Franco, D.; Netto, M.S.; Dotto, G.L.; Bajahzar, A.; Belmabrouk, H.; Bonilla-Petriciolet, A.; Li, Z. Adsorption of acid green and procion red on a magnetic geopolymer based adsorbent: Experiments, characterization and theoretical treatment. Chem. Eng. J. 2020, 383, 123113. [CrossRef]

22. Rossatto, D.I.; Netto, M.S.; Jahn, S.L.; Mallmann, E.S.; Dotto, G.I.; Foletto, E.L. Highly efficient adsorption performance of a novel magnetic geopolymer $/ \mathrm{Fe}_{3} \mathrm{O}_{4}$ composite towards removal of aqueous acid green 16 dye. J. Environ. Chem. Eng. 2020, 8, 103804. [CrossRef]

23. Hernandez-Flores, H.; Pariona, N.; Herrera-Trejo, M.; Hdz-Garcia, H.M.; Mtz-Enriquez, A.I. Concrete/maghemite nanocomposites as novel adsorbents for arsenic removal. J. Mol. Struct. 2018, 1171, 9-16. [CrossRef]

24. Maleki, A.; Hajizadeh, Z.; Sharifi, V.; Emdadi, Z. A green, porous, and eco-friendly magnetic geopolymer adsorbent for heavy metals removal from aqueous solutions. J. Clean. Prod. 2019, 215, 1233-1245. [CrossRef]

25. Zhang, Y.J.; Han, Z.C.; He, P.Y.; Chen, H. Geopolymer-based catalyst for cost-effective environmental governance: A review based on source control and end-of-pipe treatment. J. Clean. Prod. 2020, 263, 121556. [CrossRef]

26. Hajizadeh, Z.; Radinekiyan, F.; Eivazzadeh-keihan, R.; Maleki, A. Development of novel and green $\mathrm{NiFe}_{2} \mathrm{O}_{4} /$ geopolymer nanocatalyst based on bentonite for synthesis of imidazole heterocycles by ultrasonic irradiation. Sci. Rep. 2020, $10,11671$. [CrossRef]

27. Xiao, T.D.; Ma, X.Q.; Zhang, H.; Reisner, D.E.; Raj, P.M.; Wan, L.; Tummala, R. Magnetic nanocomposite paste: An ideal high- $\mu$, $\mathrm{k}$ and $\mathrm{Q}$ nanomaterial for embedded inductors in high frequency electronic applications. In Proceedings of the 9th World Multi-Conference on Systemics, Cybernetics and Informatic, Orlando, FL, USA, 10-13 July 2005.

28. Raj, P.M.; Muthana, P.; Xiao, T.D.; Wan, L.; Balaraman, D.; Abothu, I.R.; Bhattacharya, S.; Swaminathan, M.; Tummala, R. Magnetic nanocomposites for organic compatible miniaturized antennas and inductors. In Proceedings of the International Symposium on Advanced Packaging Materials: Processes, Properties and Interfaces, Irvine, CA, USA, 16-18 March 2005.

29. Komlev, A.A.; Almjashev, V.I.; Bechta, S.V.; Khabensky, V.B.; Granovsky, V.S.; Gusarov, V.V. New sacrificial material for ex-vessel core catcher. J. Nucl. Mater. 2015, 467, 778-784. [CrossRef]

30. Cantarel, V.; Motooka, T.; Yamagishi, I. Geopolymers and their potential applications in the nuclear waste management fieldA bibliographic study. JAEA Rev. 2017, 014. [CrossRef]

31. Fathi, M.; Mehdipour, M.; Shokrollahi, H. Microwave adsorption properties of nanostructure composite particles based on $\mathrm{SrFe}_{12} \mathrm{O}_{19}$. J. Aust. Ceram. Soc. 2020, 56, 251-256. [CrossRef]

32. Karahroudi, Z.H.; Hedayati, K.; Goodarzi, M. Green synthesis and characterization of hexaferrite strontium-perovskite strontium photocatalyst nanocomposites. Main Group Met. Chem. 2020, 43, 26-42. [CrossRef]

33. Mishra, D.D.; Tan, G. Visible photocatalytic degradation of methylene blue on magnetic $\mathrm{SrFe}_{12} \mathrm{O}_{19}$. J. Phys. Chem. Solids 2018, 123, 157-161. [CrossRef]

34. Bavarsiha, F.; Rajabi, M.; Montazeri-Pour, M. Synthesis of $\mathrm{SrFe}_{12} \mathrm{O}_{19} / \mathrm{SiO}_{2} / \mathrm{TiO}_{2}$ composites with core/shell/shell nano-structure and evaluation of their photo-catalytic efficiency for degradation of methylene blue. J. Mater. Sci. Mater. Electron. 2018, 29, 1877-1887. [CrossRef]

35. Ziarani, G.M.; Asl, Z.K.; Gholamzadeh, P.; Badiei, A.; Afshar, M. The use of $\mathrm{SrFe}_{12} \mathrm{O}_{19}$ magnetic nanoparticles as an efficient catalyst in the modified Niementowski reaction. Appl. Organomet. Chem. 2017, 31, e3830. [CrossRef]

36. Panpan, J.; Jinlu, D.; Jianbo, W.; Jinwu, W.; Lining, P.; Jianan, L.; Qingfang, L. Width-controlled M-type hexagonal strontium ferrite $\left(\mathrm{SrFe}_{12} \mathrm{O}_{19}\right)$ nanoribbons with high saturation magnetization and superior coercivity synthesized by electrospinning. Sci. Rep. 2015, 5, 15089. [CrossRef]

37. Ketov, S.V.; Yagodkin, Y.D.; Menushenkov, V.P. Structure and magnetic properties of strontium ferrite anisotropic powder with nanocrystalline structure. J. Alloy. Compd. 2011, 509, 1065-1068. [CrossRef]

38. Italian Version of EN 206: $2013+$ A1(2016). Concrete Specification, Performance, Production and Conformity; European Committee for Standardization CEN-CENELEC Management Centre: Brussels, Belgium, 2016.

39. Massiot, D.; Fayon, F.; Capron, M.; King, I.; Le Calvé, S.; Alonso, B.; Durand, J.O.; Bujoli, B.; Gan, Z.; Hoatson, G. Modelling oneand two-dimensional solid state NMR spectra. Magn. Reson. Chem. 2020, 40, 70-76. [CrossRef]

40. Patrakeev, M.V.; Leonidov, I.A.; Kozhevnikov, V.L.; Kharton, V.V. Ion-electron transport in strontium ferrites: Relationship. Solid State Sci. 2004, 6, 907-913. [CrossRef]

41. Eikeland, A.Z.; Stingaciu, M.; Mamakhel, A.H.; Saura-Muzquiz, M.; Christensen, M. Enhancement of magnetic properties through morphology control of $\mathrm{SrFe}_{12} \mathrm{O}_{19}$ nanocrystallites. Sci. Rep. 2018, 8, 7325-7333. [CrossRef]

42. Stingaciu, M.; Eikeland, A.Z.; Gjorup, F.H.; Deledda, S.; Christensen, M. Optimization of magnetic properties in fast consolidated $\mathrm{SrFe}_{12} \mathrm{O}_{19}$ nanocrystallites. Rcs Adv. 2019, 9, 12698-12976. [CrossRef]

43. Sun, R.; Li, X.; Xia, A.; Su, S.; Jin, C. Hexagonal $\mathrm{SrFe}_{12} \mathrm{O}_{19}$ ferrite with high saturation magnetization. Ceram. Int. 2018, 44, 13551-13555. [CrossRef]

44. Margarette, S.J.; Venkateswara Rao, A.; Vemuri, R.; Murali, N.; Ramakrishna, Y.; Veeraiah, V.; Devi, M.J. Synthesis, structural and magnetic properties of $\mathrm{SeFe}_{12} \mathrm{O}_{19}$ hexaferrites. Int. J. Sci. Technol. Res. 2019, 8, 1585-1589.

45. Zhang, T.; Peng, X.; Li, J.; Yang, Y.; Xu, J.; Wang, P.; Jin, D.; Jin, H.; Hong, B.; Wang, X.; et al. Platelet-like hexagonal SrFe ${ }_{12} \mathrm{O}_{19}$ particles: Hydrothermal synthesis and their orientation in a magnetic field. J. Magn. Magn. Mater. 2016, 412, 102-196. [CrossRef]

46. Cullity, B.D.; Graham, C.D. Introduction to Magnetic Materials, 2nd ed.; Wiley-IEEE Press: Piscataway, NJ, USA, 2009. 
47. Roberts, A.P.; Cui, Y.; Verosub, K.L. Wasp-waisted hysteresis loops: Mineral magnetic characteristics and discrimination of components in mixed magnetic systems. J. Geophys. Res. 1995, 100, 17909-17924. [CrossRef]

48. Bennett, L.H.; Della Torre, E. Analysis of wasp-waist hysteresis loops. J. Appl. Phys. 2005, 97, 10E502. [CrossRef]

49. Spizzo, F.; Sgarbossa, P.; Sieni, E.; Semenzato, A.; Dughiero, F.; Forzan, M.; Bertani, R.; Del Bianco, L. Synthesis of ferrofluids made of iron oxide nanoflowers: Interplay between carrier fluid and magnetic properties. Nanomaterials 2017, 7, 373. [CrossRef] [PubMed]

50. Coduri, M.; Masala, P.; Del Bianco, L.; Spizzo, F.; Ceresoli, D.; Castellano, C.; Cappelli, S.; Oliva, C.; Checchia, S.; Allieta, M.; et al. Local structure and magnetism of $\mathrm{Fe}_{2} \mathrm{O}_{3}$ maghemite nanocrystals: The role of crystal dimension. Nanomaterials 2020, $10,867$. [CrossRef]

51. Remya, K.P.; Prabhu, D.; Amirthapandian, S.; Viswanathan, C.; Ponpandian, N. Exchange spring magnetic behavior in $\mathrm{BaFe}_{12} \mathrm{O}_{19} / \mathrm{Fe}_{3} \mathrm{O}_{4}$ nanocomposites. J. Magn. Magn. Mater. 2016, 406, 233-238. [CrossRef]

52. Algarou, N.A.; Slimani, Y.; Almessiere, M.A.; Alahmari, F.S.; Vakhitov, M.G.; Klygach, D.S.; Trukhanov, S.V.; Trukhanov, A.V.; Baykal, A. Magnetic and microwave properties of $\mathrm{SrFe}_{12} \mathrm{O}_{19} / \mathrm{MCe}_{0.04} \mathrm{Fe}_{1.96} \mathrm{O}_{4}(\mathrm{M}=\mathrm{Cu}, \mathrm{Ni}, \mathrm{Mn}, \mathrm{Co}$ and $\mathrm{Zn})$ hard/soft nanocomposites. J. Mater. Res. Technol. 2020, 9, 5858-5870. [CrossRef]

53. Jacobo, S.E.; Bercoff, P.G.; Herme, C.A.; Vives, L.A. Sr hexaferrite/Ni ferrite nanocomposites: Magnetic behavior and microwave absorbing properties in the X-band. Mater. Chem. Phys. 2015, 157, 124-129. [CrossRef]

54. Ovejero, J.G.; Spizzo, F.; Morales, M.P.; Del Bianco, L. Mixing iron oxide nanoparticles with different shape and size for tunable magneto-heating performance. Nanoscale 2021, 13, 5714-5729. [CrossRef] [PubMed]

55. Lee, D.C.; Mikulec, F.V.; Pelaez, J.M.; Koo, B.; Korgel, B.A. Synthesis and magnetic properties of silica-coated FePt nanocrystals. J. Phys. Chem. B 2006, 110, 11160-11166. [CrossRef] [PubMed]

56. Magno De Lima Alves, T.; Amorim, B.F.; Morales Torres, M.A.; Bezerra, C.G.; De Medeiros, S.N.; Gastelois, P.L.; Fernandez Outon, L.E.; De Almeida Macedo, W.A. Wasp-waisted behavior in magnetic hysteresis curves of $\mathrm{CoFe}_{2} \mathrm{O}_{4}$ nanopowder at a low temperature: Experimental evidence and theoretical approach. Rsc Adv. 2017, 7, 22187-22196. [CrossRef]

57. Stoner, E.C.; Wohlfarth, E.P. A mechanism of magnetic hysteresis in heterogeneous alloys. IEEE Trans. Magn. 1991, 27, 3475-3518. [CrossRef]

58. Kechrakos, D.; Trohidou, K. Magnetic properties of dipolar interacting single-domain particles. Phys. Rev. B Condens. Matter Mater. Phys. 1998, 58, 12169-12177. [CrossRef]

59. Schrefl, T.; Schmidts, H.F.; Fidler, J.; Kronmüller, H. The role of exchange and dipolar coupling at grain boundaries in hard magnetic materials. J. Magn. Magn. Mater. 1993, 124, 251-261. [CrossRef]

60. Zeng, H.; Sun, S.; Vedantam, T.S.; Liu, J.P.; Dai, Z.R.; Wang, Z.L. Exchange-coupled FePt nanoparticle assembly. Appl. Phys. Lett. 2002, 80, 2583-2585. [CrossRef]

61. Lee, W.K.W.; van Deventer, J.S.J. Use of infrared spectroscopy to study geopolymerization of heterogeneous amorphous aluminosilicates. Langmuir 2003, 19, 8726-8734. [CrossRef]

62. Valcke, S.L.A.; Pipilikaki, P.; Fischer, H.R.; Verkuijlen, M.H.W.; van Eck, E.R.H. FT-IR and ${ }^{29}$ Si NMR for evaluating aluminumsilicate precursors for geopolymers. Mater. Struct. 2015, 48, 557-569. [CrossRef]

63. Mikhailova, O.; del Campo, A.; Rovnanik, P.; Fernandez, J.F.; Torres-Carrasco, M. In situ characterization of main reaction propducts in alkali-activated slag materials by Confocal Raman Microscopy. Cem. Concr. Compos. 2019, 99, 32-39. [CrossRef]

64. Walkey, B.; Provis, J.I. Solid-state nuclear magnetic resonance spectroscopy of cements. Mater. Today Adv. 2019, 1, 100007. [CrossRef]

65. Dupuy, C.; Gharzouni, A.; Sobrados, I.; Texier-Mandoki, N.; Bourbon, X.; Rossignol, S. ${ }^{29} \mathrm{Si},{ }^{27} \mathrm{Al},{ }^{31} \mathrm{P}$ and ${ }^{11} \mathrm{~B}$ magic angle spinning nuclear magnetic resonance study of the structural evolutions induced by the use of phosphor- and boron-based additives in geopolymer mixtures. J. Non Cryst. Solids 2019, 521, 119541. [CrossRef]

66. Autef, A.; Joussein, E.; Gasgnier, G.; Pronier, S.; Sobrados, I.; Sanz, J.; Rossignol, S. Role of metakaolin dehydroxylation in geopolymer synthesis. Powder Technol. 2013, 250, 33-39. [CrossRef]

67. Buchwald, A.; Hilbig, H.; Kaps, C. Alkali-activated metakaolin-slag blends performance and structure in dependence of their composition. J. Mater. Sci. 2007, 42, 3024-3032. [CrossRef]

68. Ferone, C.; Colangelo, F.; Roviello, G.; Asprone, D.; Menna, D.; Balsamo, A.; Prota, A.; Cioffi, R.; Manfredi, G. Application-oriented chemical optimization of a metakaolin based geopolymer. Materials 2013, 6, 1920-1939. [CrossRef]

69. Subaer, J.; van Riessen, A. Thermo-mechanical and microstructural characterization of sodium-poly(sialate-siloxo) (Na-PSS) geopolymers. J. Mater. Sci. 2007, 42, 3117-3123. [CrossRef]

70. Rosas-Casarez, C.A.; Arredondo-Rea, S.P.; Gomez-Soberon, J.M.; Alamaral-Sanchez, J.L.; Corral-Higuera, R.; ChinchillasChinchillas, M.J.; Acuna-Aguero, O.H. Experimental study of XRD, FTIR and TGA techniques in geopolymeric materials. Int. J. Adv. Comput. Sci. Appl. 2014, 4, 221-225.

71. Iwahiro, T.; Nakamura, Y.; Komatsu, R.; Ikeda, K. Crystallization behavior and characteristics of mullites formed from aluminasilica gels prepared by the geopolymer technique in acidic conditions. J. Eur. Ceram. Soc. 2001, 21, 2515-2519. [CrossRef]

72. Erb, R.M.; Martin, J.J.; Soheilian, R.; Pan, C.; Barber, J.R. Actuating soft matter with magnetic torque. Adv. Funct. Mater. 2016, 26, 3859-3880. [CrossRef]

73. McCarter, W.J.; Taha, H.M.; Suryanto, B.; Starrs, G. Two-poin concrete resistivity measurements: Interfacial phenomena at the electrode-concrete contact zone. Meas. Sci. Technol. 2015, 26, 085007. [CrossRef] 
74. Zeng, S.; Wang, J. Characterization of mechanical and electric properties of geopolymers synthesized using four locally available fly ashes. Constr. Build. Mater. 2016, 121, 386-399. [CrossRef]

75. Hu, X.; Shi, C.; Liu, X.; Zhang, J.; Schutter, G. A review on microstructural characterization of cement-based materials by AC impedances specttroscopy. Cem. Concr. Compos. 2019, 100, 1-14. [CrossRef]

76. Hu, X.; Shi, C.; Liu, X.; Zhang, Z. Study of the effect of alkali dosage on microstructure development of alkali-activated slag pastes by electrical impedance spectroscopy (EIS). Constr. Build. Mater. 2020, 261, 119982. [CrossRef]

77. Song, Q.; Wang, J.; Dong, T.; He, L.; Lu, S. Study of the alkali activated geopolymer by AC impedances spectroscopy. IOP Conf. Ser. Earth Environ. Sci. 2019, 267, 022001. [CrossRef]

78. Cui, X.-M.; Zheng, G.J.; Han, Y.C.; Su, F.; Zhou, J. A study of electrical conductivity of chemosynthetic $\mathrm{Al}_{2} \mathrm{O}_{3}-2 \mathrm{SiO}_{2}$ geopolymer materials. J. Powder Sources 2008, 184, 652-656. [CrossRef]

79. Chuewangkam, N.; Pinitsoontorn, S.; Chindaprasirt, P. Properties of NdFeB magnetic cement. Cem. Concr. Compos. 2019, 103, 204-212. [CrossRef] 